\title{
Optimum Plot Size and Number of Replications with Short-day Onions for Yield, Seedstem Formation, Number of Doubles, and Incidence of Foliar Diseases
}

\author{
George E. Boyhan ${ }^{1}$ \\ University of Georgia, Dept. of Horticulture, East Georgia Extension Center, P.O. Box 8112, GSU, \\ Statesboro, GA 30460 \\ David B. Langston ${ }^{2}$ \\ University of Georgia, Dept. of Plant Pathology, Rural Development Center, P. O. Box 1209, Tifton, \\ GA 31793
}

\author{
Albert C. Purvis ${ }^{3}$ \\ University of Georgia, Dept. of Horticulture, Coastal Plain Experiment Station, Tifton, GA 31793 \\ C. Randell Hill ${ }^{4}$ \\ Vidalia Onion and Vegetable Research Center, 8163 Hwy. 178, Lyons, GA 30436
}

AdDitional INDEX words. Allium cepa, Vidalia, sweet onions, variety evaluation, Granex, Alliaceae

\begin{abstract}
Five different statistical methods were used to estimate optimum plot size and three different methods were used to estimate optimum number of replications with short-day onions (Allium cepa L.) for yield, seedstem formation (bolting), purple blotch and/or Stemphylium (PB/S), botrytis leaf blight (BLB), and bulb doubling with a basic plot size unit of $1.5 \times 1.8 \mathrm{~m}$ (length $\times$ width). Methods included Bartlett's test for homogeneity of variance, computed LSD values, maximum curvature of coefficient of variation plotted against plot size, Hatheway's method for a true mean difference, and Cochran and Cox's method for detecting a percent mean difference. Bartlett's chi-square was better at determining optimum plot size with transformed count and percent data compared with yield data in these experiments. Optimum plot size for yield of five basic units $(7.5 \mathrm{~m}$ length) and four replications is indicated using computed LSD values where the LSD is $<5 \%$ of the average for that plot size, which was the case in both years of this study. Based on all the methods used for yield, a plot size of four to five basic units and three to five replications is appropriate. For seedstems using computed LSD values, an optimum plot size of four basic units $(6 \mathrm{~m}$ length) and two replications is indicated. For PB/S two basic units ( $3 \mathrm{~m}$ length) plot size with four replications is indicated by computed LSD values. For BLB a plot size of four basic units (6 m length) and three replications is optimum based on computed LSD values. Optimum plot size and number of replications for estimating bulb doubling was four basic units $(6 \mathrm{~m}$ length) and two replications with 'Southern Belle', a cultivar with a high incidence of doubling using computed LSD values. With 'Sweet Vidalia', a cultivar with low incidence of bulb doubling, a plot size of four basic units $(6 \mathrm{~m}$ length) and five replications is recommended by computed LSD values. Visualizing maximum curvature between coefficient of variation and plot size suggests plot sizes of seven to eight basic units (10.5 to $12 \mathrm{~m}$ length) for yield, 10 basic units (15 m length) for seedstems, five basic units (7.5 m length) for PB/S and BLB, five basic units (7.5 m length) for 'Southern Belle' doubling, and 10 basic units $(15 \mathrm{~m}$ length) for 'Sweet Vidalia' doubling. A number of plot size-replication combinations were optimum for the parameters tested with Hatheway's and Cochran and Cox's methods. Cochran and Cox's method generally indicated a smaller plot size and number of replications compared to Hatheway's method regardless of the parameter under consideration. Overall, both Hatheway's method and computed LSD values appear to give reasonable results regardless of data (i.e., yield, seedstems, diseases etc.) Finally, it should be noted that the size of the initial basic unit will have a strong influence on the appropriate plot size.
\end{abstract}

Optimum plot size and number of replications for yield have been estimated for several different crops, both agronomic and horticultural (Gupta and Raghavarao, 1971; Saito and Ohtake, 1996; Shamasundaran and Bhat, 1997; Singh, 1989; Szunics and Balla, 1975; Thomas and Abou-El Fittouh, 1968). Singh (1989) in uniformity trials with chile peppers (Capsicum annuит L.) found an optimum plot size of 6 to $8 \mathrm{~m}^{2}$ with 30 to 40 plants. Optimum plot size was estimated to be $7.2 \mathrm{~m}^{2}$ with 16 rows $1 \mathrm{~m}$ in length with $45 \mathrm{~cm}$ between rows for 'Lowker' potato (Solanum tuberosum L.) (Bhatt et al., 1998). Oliveira and Estefanel (1995)

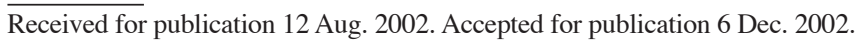
${ }^{1}$ Assistant professor, extension horticulturist-vegetables, corresponding author, e-mail gboyhan@uga.edu.

${ }^{2}$ Assistant professor.

${ }^{3}$ Professor.

${ }^{4}$ Research station superintendent. found the optimum plot size for 'Baronesa' potato was $16 \mathrm{~m}^{2}$ with a between row spacing of $80 \mathrm{~cm}$ and a within row spacing of $33 \mathrm{~cm}$. With chickpea (Cicer arietinum L.) the optimum plot size was $5 \mathrm{~m}^{2}$ (Singh et al., 1998), which contrasts with Lakhera et al. (1995) who found an optimum plot size of $4 \mathrm{~m}^{2}$ with 3 replications. In a 3-year trial in Egypt, with faba bean (Vicia faba L.) yield, the optimum plot size was estimated to be $0.6 \mathrm{x}$ $3.5 \mathrm{~m}$ (Saad, 1996). Plot size with cabbage was estimated to be optimum with a size of 5.0 to $6.5 \mathrm{~m}^{2}$ (Singh, 1989). Vallejo and Mendoza (1992) found that an optimum plot size of between 5 and $18 \mathrm{~m}^{2}$ depending on the test used with 4 replications with sweetpotato (Ipomoea batatas Lam).

Optimum plot size studies of characteristics other than yield have also been investigated. Sharma and Misra (2000) have investigated the optimum plot size for estimating white grub (Brahmina coriacea Hope) damage in potato. Optimum plot size 
has also been estimated for some diseases. Esquivel and Lopez (1997) investigated optimum plot size for sampling root-knot nematode [Meloidogyne incognita (Kofoid \& White) Chitwood] incidence in tobacco (Nicotiana tabacum L.). Urbano et al. (1994) investigated the incidence of late blight [Phytophthora infestans (Mont.) de Bary] in potato and found that single plant plots were inadequate in detecting differences.

Optimum plot size and number of replications have also been investigated among the alliums. Peiretti et al. (1990) found an optimum plot size of 3 to $4 \mathrm{~m}^{2}$ for 'Alpa Suquia' garlic (Allium sativum L.) with a $0.65 \mathrm{~m}$ between-row spacing and $0.15 \mathrm{~m}$ between-plant spacing. Forty-eight plants per plot with three replications was found to be optimum for testing three onion (Allium cepa L.) cultivars: Arka Niketan, Arka Pragathi and Arka Kalyan (Ramachander and Pathak, 1989). This contrasts with Gupta and Raghavarao (1971) who found an optimum plot size for onion yield to be $75 \times 450 \mathrm{~cm}$ with $15 \mathrm{~cm}$ between rows and $10 \mathrm{~cm}$ between plants, which translates into 225 plants.

Short-day onions are an important crop in southeast Georgia with an estimated farmgate value of almost $\$ 95$ million in 2000 (Doherty and Mizelle, 2001). Because of the importance of the crop to the region, the Georgia Department of Agriculture has mandated that new onion cultivars undergo three years of favorable testing before they can be accepted as Vidalia onions. Although the testing for acceptance focuses on flavor and mildness, growers and seed companies are interested in other characteristics including yield, disease resistance, and other quality parameters. The objective of this study was to determine the optimum plot size and number of replications to detect differences in field yield, number of doubles, seedstem formation, and reaction to certain foliar diseases in short-day onions.

\section{Materials and Methods}

In the 1999-2000 season 'Sweet Vidalia' onions were transplanted to their final spacing on 7 Dec. 1999 and were harvested on 8 May 2000. In the 2000-01 season 'King Midas' onions were transplanted to their final spacing on 28 Nov. 2000 and harvested on 26 Apr. 2001. Onions were grown using University of Georgia soil test recommendations for fertility and cooperative extension service recommendations for disease, insect, and weed control. Onions were transplanted on $1.2 \mathrm{~m}$ wide raised beds with a bed height of $10 \mathrm{~cm}$. Beds were formed with a $1.8 \mathrm{~m}$ center-to-center spacing. Four rows of onions were transplanted on a bed with a between-row spacing of $30 \mathrm{~cm}$ and an in-row spacing of $15 \mathrm{~cm}$.

Onions were harvested from a single bed in $1.5 \mathrm{~m}$ length plots (basic unit $2.7 \mathrm{~m}^{2}$ ). During the 1999-2000 season, $80 \mathrm{such}$ plots were harvested and in the 2000-01 season 70 plots were harvested. Field weights were recorded for each plot after the tops and roots were removed.

In the 2001-02 season, additional parameters were measured including number of seedstems (bolting), number of doubled bulbs, incidence of Stemphylium leaf blight [Stemphylium vesicarium (Wallr.) E. Simmons] and/or purple blotch [Alternaria porri (Ellis) Cif.], and incidence of Botrytis leaf blight (BLB) (Botrytis squamosa J.C. Walker). Lesions of Stemphylium leaf blight (S) and purple blotch (PB) are difficult to distinguish without microscopic evaluation therefore they were counted together. Plots were planted to their final spacing on 26 Nov. 2001 and evaluated on 26 Mar. 2002. Eighty basic unit sized plots were measured for seedstems, BLB, and PB/S with cultivar Sweet
Vidalia. Seedstems and PB/S lesions were counted and recorded for each basic unit plot. BLB was measured as a percent of leaf area affected for each basic unit plot. Eighty basic unit sized plots of 'Sweet Vidalia' and forty basic unit sized plots of 'Southern Belle' were evaluated for number of doubles. Both counts and percentages were transformed with square root $(x+0.5)$ where $x$ is the individual count or percent before calculations (Little and Hills, 1978). All such transformed data were back-transformed after calculations.

Between plot variances, variances per unit area, coefficient of variabilities, and Smith's adjusted index of soil heterogeneity for each year were calculated (Gomez and Gomez, 1984). Bartlett's chi-square test for homogeneity of variance was calculated for all possible comparisons of per unit area variances (Gomez and Gomez, 1994).

Least significant difference (LSD) values were calculated for different plot sizes and replications using 30 degrees of freedom for treatments and $P \leq 0.05$ (Rampton and Petersen, 1962). Hatheway's method, which is an estimate of true differences as a percent of the mean, was estimated by the formula: $\mathrm{d}^{2}=2\left(\mathrm{t}_{1}\right.$ $\left.+t_{2}\right)^{2} \mathrm{CV} / \mathrm{rx}^{\mathrm{b}}$, where $\mathrm{d}$ is the true difference between two treatments as a percent of the mean, $t_{1}$ is the significant value of $t$ at 0.05 probability, $t_{2}$ is the value of $t$ corresponding to $2(1-\mathrm{P})$ where $\mathrm{P}$ is the probability of obtaining a significant result $(80 \%$ in this case), $\mathrm{CV}$ is the coefficient of variability, $\mathrm{r}$ is the number of replications, $\mathrm{x}$ is the plot size in basic units, and b is Smith's adjusted index for soil heterogeneity (Gomez and Gomez, 1984; Hatheway, 1961).

Cochran and Cox's method for detecting a true difference as a percent of the mean is $\delta=\sqrt{ }(2 / r) \sigma\left(t_{1}+t_{2}\right)$ where $r, t_{1}$, and $t_{2}$ are as defined above and $\sigma$ is the true standard error per unit (square root of the variance per unit area) (Cochran and Cox, 1957). Microsoft Excel 2001 was used to calculate statistics including power trendlines of coefficient of variation by plot size and Cochran and Cox's calculations.

\section{Results}

YIELD. Table 1 lists the between-plot variance, variance per unit area, and coefficient of variability for field yield. Bartlett's chi-square for homogeneity of variance indicated significant differences in variances between plot sizes with basic units of one and two, two and four, five and eight, and finally 16 and 20 in the 1999-2000 season. In the 2000-01 season, the 35 basic unit plot size variance was significantly lower than the seven basic unit plot size but did not differ from plot sizes of 10 or 14 basic units. Plot sizes of five, seven, 10, and 14 basic units did not differ from each other. Plot size of seven basic units differed significantly from plot sizes of one and two basic units.

LSD values were computed for each plot size and replication combination for both the 1999-2000 and 2000-01 seasons (Table 2). A plot size of five basic units with four replications had an LSD of $4.19 \mathrm{~kg}$, which is less than $5 \%$ of the average yield of 88.6 $\mathrm{kg}$ for that size plot in the 1999-2000 season. In the 2000-01 season, a plot size of five basic units and four replications had an LSD of $1.85 \mathrm{~kg}$ which is less than $5 \%$ of the average yield of $42.6 \mathrm{~kg}$ for that plot size.

The plotted power trendlines of coefficient of variability against plot sizes had maximum curvature around eight basic units plot size for the 1999-2000 season and around seven basic units plot size for the 2000-01 season (Fig. 1). The equation for the 1999-2000 trendline was $\mathrm{y}=1.4456 \mathrm{x}^{-1.3385}$ and the $R^{2}$ was 0.9982 . 
Table 1. Between plot variance $\left[\mathrm{V}_{(\mathrm{x})}\right]$, variance per unit area $\left(\mathrm{V}_{\mathrm{x}}\right)$, and coefficient of variability for the 1999-2000 and 2000-01 seasons for short-day onions grown in Georgia.

\begin{tabular}{|c|c|c|c|c|}
\hline $\begin{array}{l}\text { Basic } \\
\text { units } \\
\end{array}$ & $\begin{array}{c}\text { Between plot } \\
\text { variance } \\
\mathrm{V}_{(\mathrm{x})} \\
\end{array}$ & $\begin{array}{c}\text { Variance per } \\
\text { unit area } \\
\mathrm{V}_{\mathrm{x}} \\
\end{array}$ & df & $\begin{array}{c}\text { Coefficient } \\
\text { of variability } \\
(\%)\end{array}$ \\
\hline \multicolumn{5}{|c|}{ 1999-2000 Season } \\
\hline 1 & 712.1 & $712.1 \mathrm{a}^{\mathrm{z}}$ & 79 & 150.5 \\
\hline 2 & 354.6 & $88.6 \mathrm{~b}$ & 39 & 53.1 \\
\hline 4 & 265.7 & $16.6 \mathrm{c}$ & 19 & 23.0 \\
\hline 5 & 223.8 & $9.0 \mathrm{c}$ & 15 & 16.9 \\
\hline 8 & 145.0 & $2.3 \mathrm{~d}$ & 9 & 8.5 \\
\hline 10 & 177.3 & $1.8 \mathrm{~d}$ & 7 & 16.9 \\
\hline 16 & 98.3 & $0.4 \mathrm{~d}$ & 4 & 3.5 \\
\hline 20 & 72.2 & $0.2 \mathrm{e}$ & 3 & 2.4 \\
\hline 40 & 58.2 & $0.0 \mathrm{e}$ & 1 & 1.1 \\
\hline \multicolumn{5}{|c|}{ 2000-01 Season } \\
\hline 1 & 127.9 & $127.9 \mathrm{a}^{\mathrm{z}}$ & 69 & 132.7 \\
\hline 2 & 82.6 & $20.6 \mathrm{ab}$ & 34 & 53.3 \\
\hline 5 & 43.8 & $1.8 \mathrm{bc}$ & 13 & 15.5 \\
\hline 7 & 46.1 & $0.9 \mathrm{c}$ & 9 & 11.4 \\
\hline 10 & 15.7 & $0.2 \mathrm{~cd}$ & 6 & 4.6 \\
\hline 14 & 34.4 & $0.2 \mathrm{~cd}$ & 4 & 4.9 \\
\hline 35 & 0.1 & $0.0 \mathrm{~d}$ & 1 & 0.1 \\
\hline
\end{tabular}

${ }^{z}$ Separation by Bartlett's chi-square test for homogeneity of variance $(P \leq 0.05)$.

For the 2000-01 trendline the equation was $\mathrm{y}=2.3066 \mathrm{x}^{-1.8204}$ and the $R^{2}$ was 0.8972 .

Using Hatheway's method, several combinations of plot sizes and replications resulted in detecting true differences as a percent of the mean below 20\% (Fig. 2 and 3). A plot size of four basic units combined with six replications results in a detectable difference of $18.8 \%$ of the mean in the 1999-2000 season. Other combinations for the 1999-2000 season that meet the criteria include plot sizes of five basic units and five replications (17.8\%), as well as eight basic units and three replications (18.1\%). All plot sizes with basic units of 16 or above regardless of the number of replications had detectable differences below $20 \%$.

In the 2000-01 season, a plot size of five basic units combined with five replications resulted in a detectable difference of $17.0 \%$. Combinations of seven basic units and four replications (16.1\%), as well as 10 basic units and two replications (18.3\%) also resulted in detectable differences below $20 \%$. Plot sizes of 14 and 35 basic units regardless of the number of replications had detectable differences below $20 \%$.

Power trendlines of Cochran and Cox's method for the 19992000 and 2000-01 seasons are shown in Fig. 4 and 5. Detection of a true difference as a percent of the mean below $10 \%$ was possible in the 1999-2000 season with a plot size of two basic units with seven replications. In addition, a plot size of four basic units and three replications also gave similar results. Plot sizes of 5, 8, 10, 16,20 , and 40 basic units, regardless of the number of replications, had detectable differences below 10\% in the 1999-2000 season. All of the power trendlines in the 1999-2000 season had $R^{2}$ values above 0.95 .

In the 2000-01 season a plot size of two basic units and four replications had a detectable difference below $10 \%$. Plot sizes of $5,7,10,14$, and 35 all had detectable differences below $10 \%$ regardless of the number of replications (Fig. 5). The $R^{2}$ values for these trendlines were all above 0.73 .

SEedSTEM Formation. For seedstems, Bartlett's chi-square was significant between one and two basic units as well as between two

Table 2. Computed LSD values and average yields based on number of replications and plot size $(P \leq 0.05$, treatment $\mathrm{df}=30)$ for short-day onions grown in Georgia.

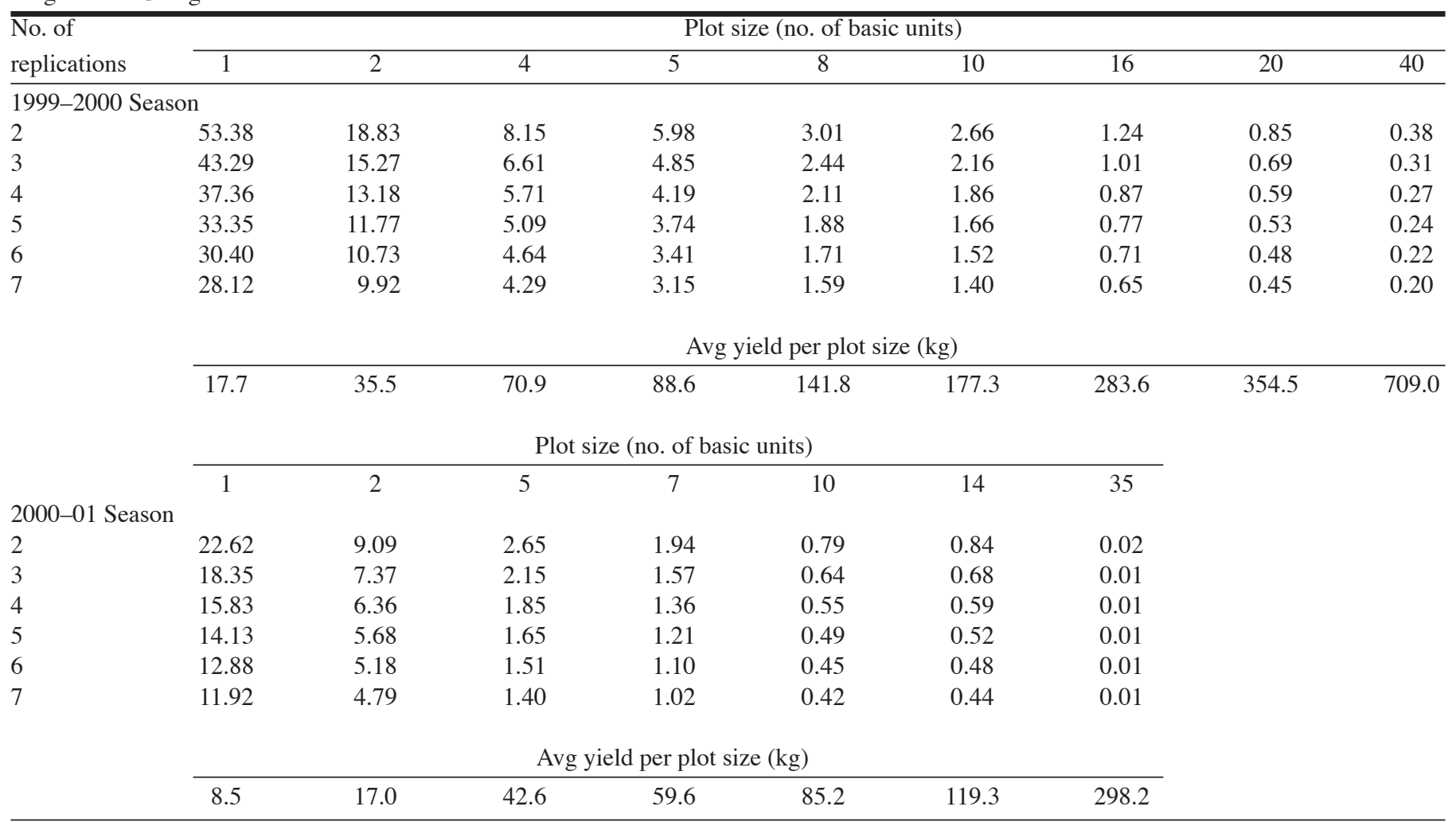


and four basic units (Table 3). Significant differences were also detected between five and eight basic units and 16 and 20 basic units. Computed LSD values with two replications and a plot size of four basic units were below $5 \%$ of the mean number of seedstems (82) for that particular plot size (Table 4). Computed LSD values for plots of eight basic units and above are not shown because these

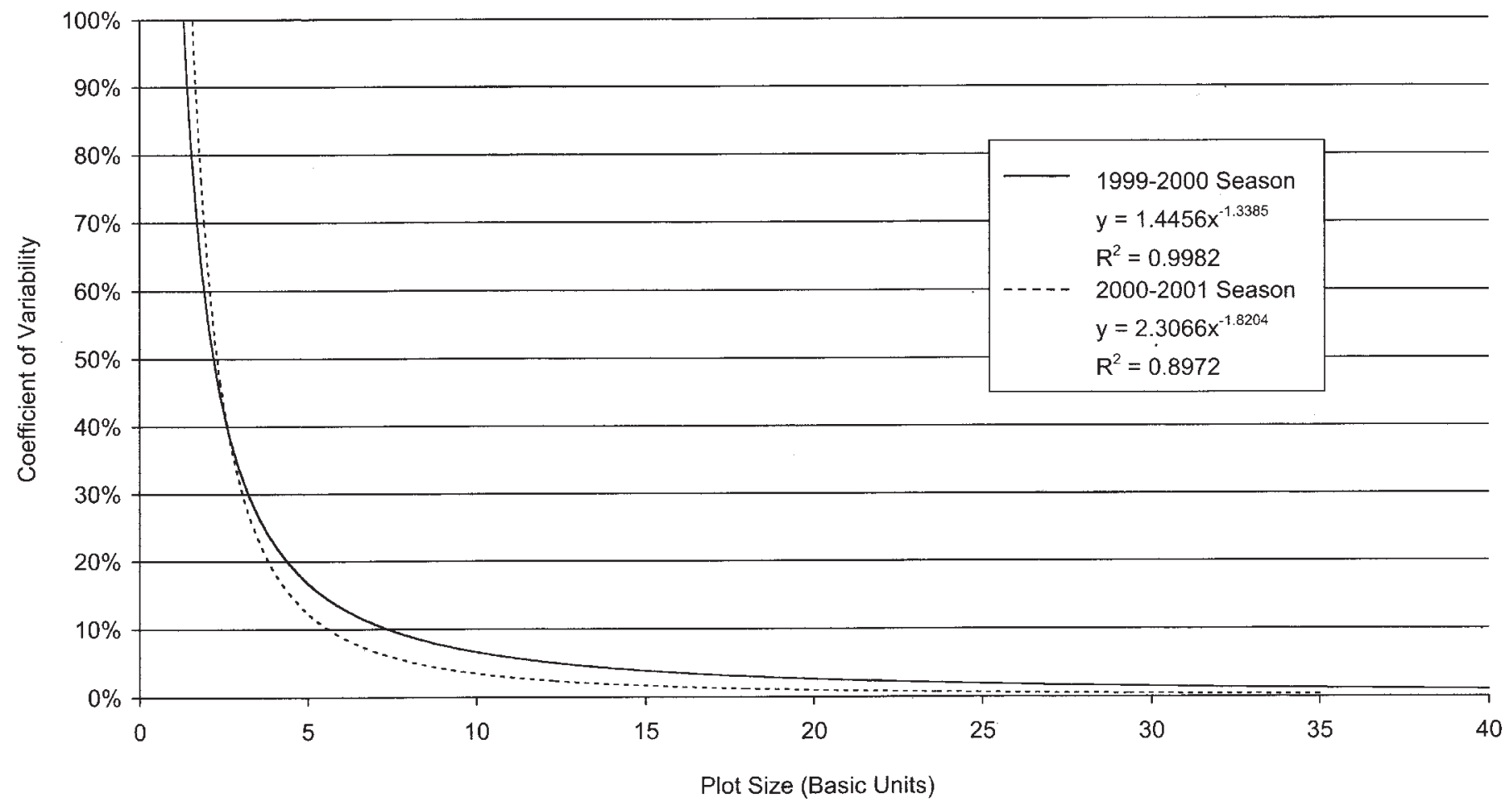

Fig. 1. Power trendline plots of coefficients of variability against plot sizes for yield.

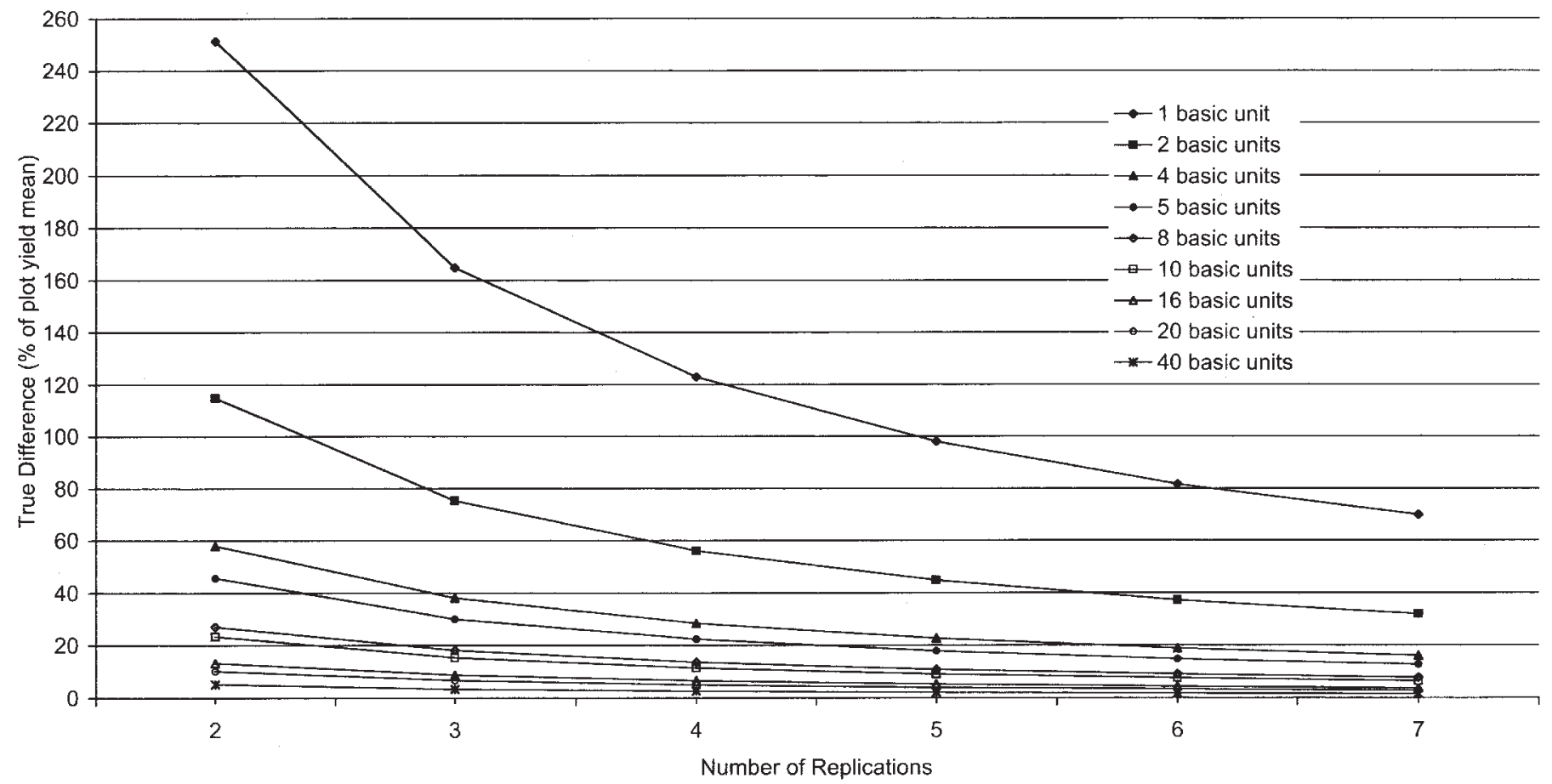

Fig. 2. Hatheway's Method for true yield differences as affected by the number of replications and plot size (1999-2000 season). 


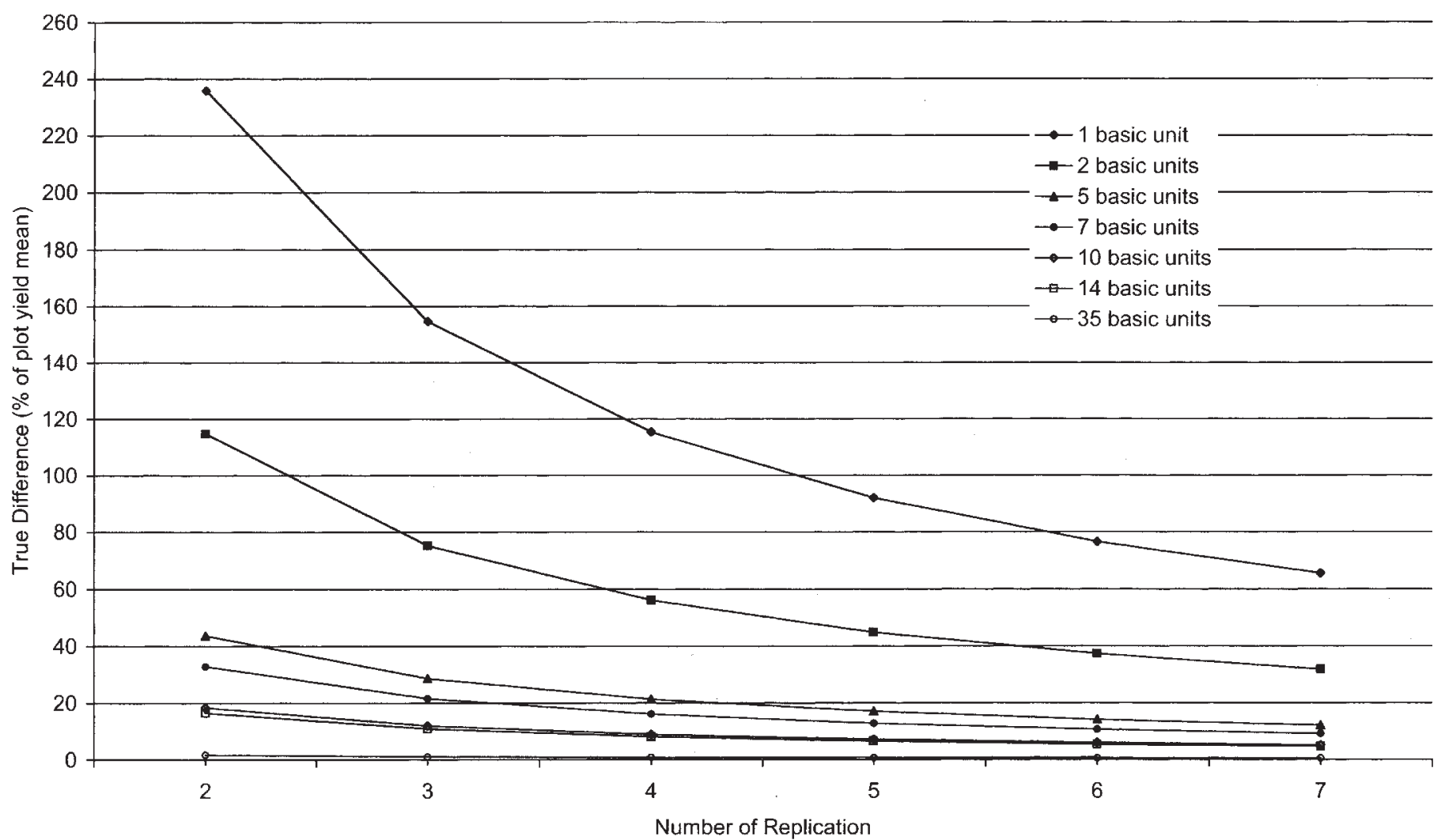

Fig. 3. Hatheway's Method for true yield differences as affected by the number of replications and plot size (2000-01 season).

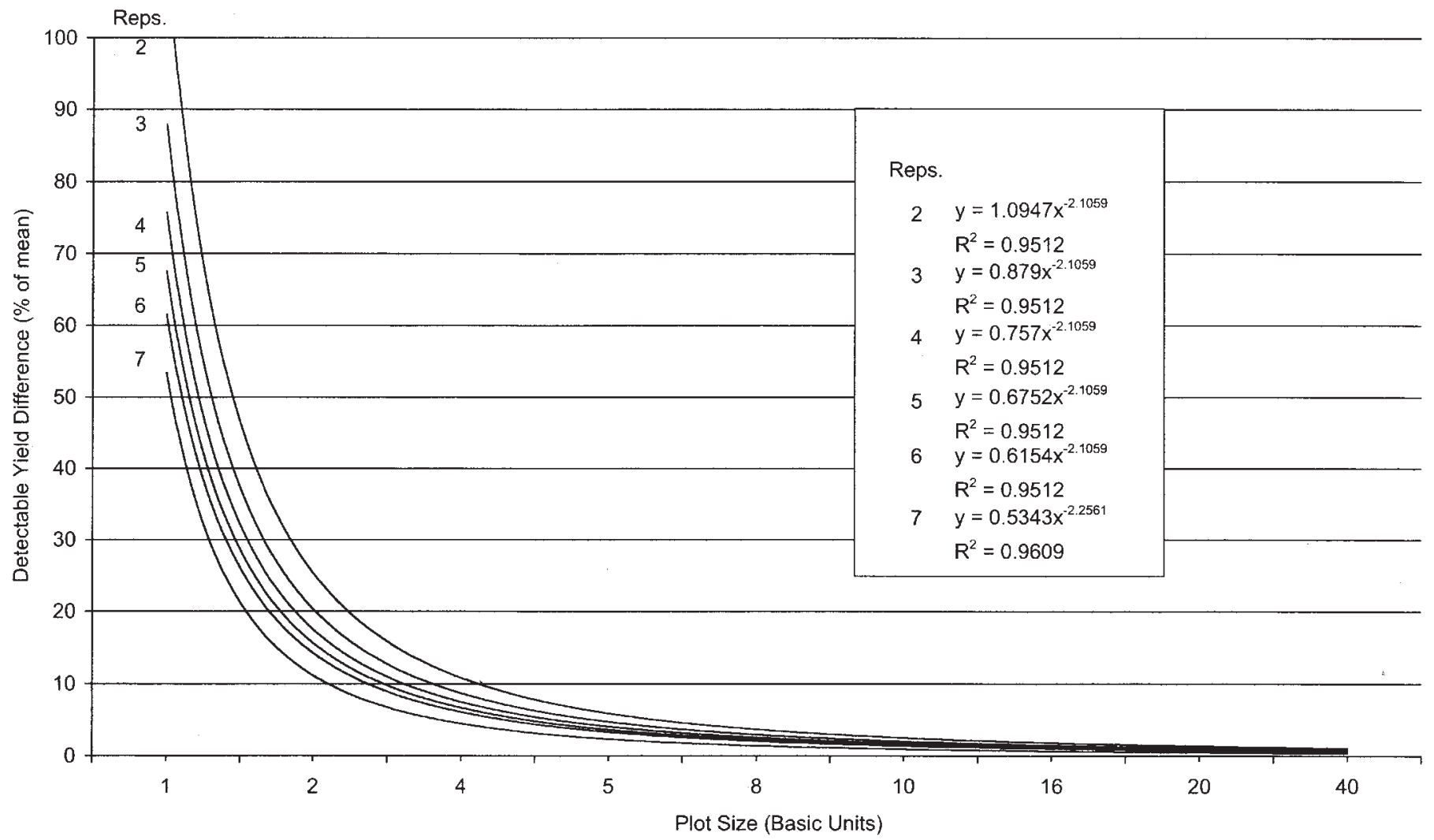

Fig. 4. Power trendlines for detectable yield differences as a function of plot size for different number of replications (1999-2000 season). 


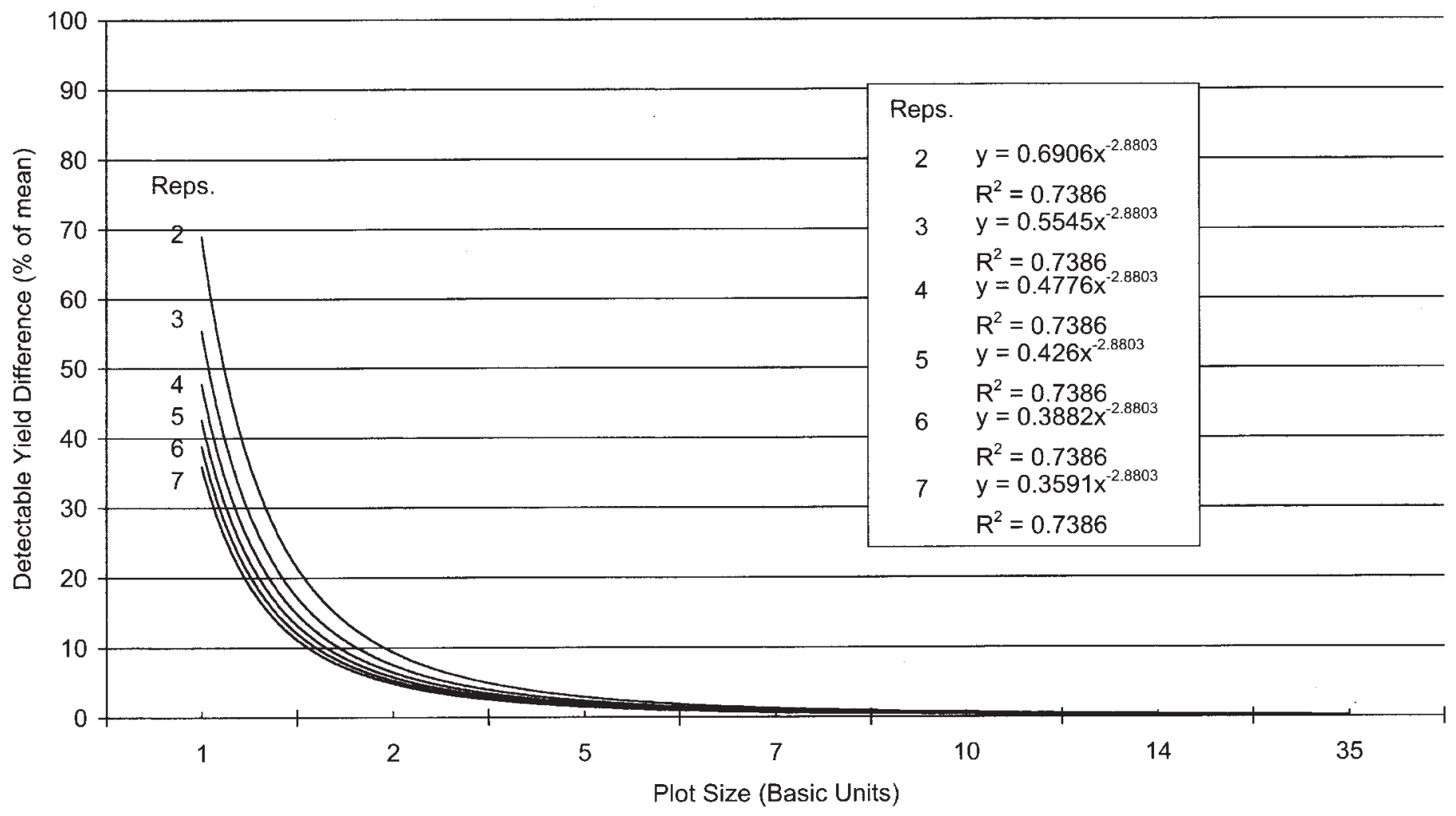

Fig. 5. Power trendlines for detectable yield differences as a function of plot size for different number of replications (2000-01 Season).

values are negative (an anomaly of back transforming the data).

The power trendline for plot size by coefficient of variability for seedstems had a maximum curvature around 10 basic units with an $R^{2}$ of 0.99 (Fig. 6). By Hatheway's method all plots with basic units of 16, 20 or 40 basic units had true differences as a percent of the mean at or below 20\% except for a plot size of 16 basic units and two replications, which had a true difference of $21.1 \%$ (Fig. 7). Plot size of eight basic units and five replications also had detectable differences below $20 \%$ as did plot sizes of 10 basic units and four replications.

Power trendlines of Cochran and Cox's method for seedstems indicate any number of replications with a plot size of two basic units will have detectable differences below $10 \%$ of the mean (Fig. 8 ). With four basic unit plot sizes, detectable differences well below $4 \%$ of the mean can be detected regardless of the number of replications. The $R^{2}$ for all of these trendlines were above 0.91 .

Number OF DOUbLe Bulb FORMATION. Because of the dramatic difference in the number of doubled bulbs between cultivars Sweet Vidalia and Southern Belle, both cultivars were evaluated for this characteristic. Differences in variances by Bartlett's chi-square were detected between plot sizes of one and two and two and four basic units for 'Southern Belle' and 'Sweet Vidalia' (Table 5). In addition, 'Sweet Vidalia' had differences between variances of plot sizes with five and eight basic units. Computed LSD values for both 'Southern Belle' and 'Sweet Vidalia' are shown in Table 6. With 'Southern Belle', an LSD of 0.85 is only $3 \%$ of the average number of 28 doubles with a plot size of four basic units and two replications. With a plot size of four basic units and three replications an LSD of 0.36 doubles represents only $1.3 \%$ of the mean number of doubles for 'Southern Belle'. This contrasts with 'Sweet Vidalia' where the same basic plot sizes and number of replications represent $48 \%$ and $23 \%$ of the mean. To get comparable values for 'Sweet Vidalia' would require a plot size of four basic units and five replications. As mentioned above, several LSD values are not reported due to an anomaly of back transforming where the values are below 0 .

Trendlines of the coefficient of variability plotted against plot size for doubles indicated that the maximum curvature occurs around five basic-unit plot size for 'Southern Belle' and 10 basic-unit plot size for 'Sweet Vidalia'. True mean differences by Hatheway's method below $20 \%$ occur with a plot size of four basic units and seven replications for doubles of 'Southern Belle' (Fig. 9). A plot size of five basic units with five replications results in a true mean difference of $21 \%$. In addition, plot sizes with eight and 10 basic units and three replications are below $20 \%$ of the mean for 'Southern Belle' doubles as are all the replications with 20 basic unit plot sizes. With Cochran and Cox's method, all of

Table 3. Between plot variance $\left[\mathrm{V}_{(\mathrm{x})}\right]$, variance per unit area $\left(\mathrm{V}_{\mathrm{x}}\right)$, and coefficient of variability for seedstems with short-day onions variety Sweet Vidalia grown in Georgia.

\begin{tabular}{lcccc}
\hline $\begin{array}{l}\text { Basic } \\
\text { unit }\end{array}$ & $\begin{array}{c}\text { Between plot } \\
\text { variance }\end{array}$ & $\begin{array}{c}\text { Variance per } \\
\text { unit area }\end{array}$ & $\begin{array}{c}\text { Coefficient } \\
\text { of variability }\end{array}$ \\
\hline 1 & $\mathrm{~V}_{(\mathrm{x})}$ & $\mathrm{V}_{\mathrm{x}}$ & $\mathrm{df}$ & $(\%)$ \\
2 & 28.4 & $28.42 \mathrm{a}^{\mathrm{z}}$ & 79 & 342.7 \\
4 & 18.4 & $4.60 \mathrm{~b}$ & 39 & 137.9 \\
5 & 12.4 & $0.78 \mathrm{c}$ & 19 & 56.7 \\
8 & 12.8 & $0.51 \mathrm{c}$ & 15 & 46.1 \\
10 & 7.5 & $0.12 \mathrm{~d}$ & 9 & 22.0 \\
16 & 9.9 & $0.10 \mathrm{~d}$ & 7 & 20.3 \\
20 & 4.7 & $0.02 \mathrm{~d}$ & 4 & 8.7 \\
40 & 3.7 & $0.01 \mathrm{e}$ & 3 & 6.2 \\
\hline
\end{tabular}

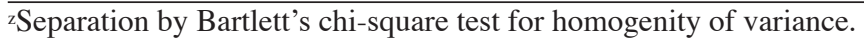


Table 4. Computed LSD values for seedstems based on number of replications and plot size $(P \leq 0.05$, treatment $\mathrm{df}=30)$ for short-day onions variety Sweet Vidalia grown in Georgia.

\begin{tabular}{|c|c|c|c|c|c|c|c|c|c|}
\hline & \multicolumn{9}{|c|}{ Plot size (no. of basic units) } \\
\hline & 1 & 2 & 4 & 5 & $8^{z}$ & $10^{z}$ & $16^{z}$ & $20^{z}$ & $40^{z}$ \\
\hline \multicolumn{10}{|c|}{ Replication } \\
\hline 3 & 75.31 & 7.27 & 1.57 & 0.87 & --- & --- & --- & --- & --- \\
\hline 4 & 55.59 & 8.58 & 1.03 & 0.51 & --- & --- & --- & --- & --- \\
\hline 5 & 44.07 & 6.71 & 0.72 & 0.30 & --- & --- & --- & --- & --- \\
\hline & \multicolumn{9}{|c|}{ Avg number of seedstems } \\
\hline & 5 & 20 & 82 & 129 & 331 & 517 & 1324 & 2070 & 8281 \\
\hline
\end{tabular}

zBecause of an anomaly in back transforming these data, those values below 0 are not shown.

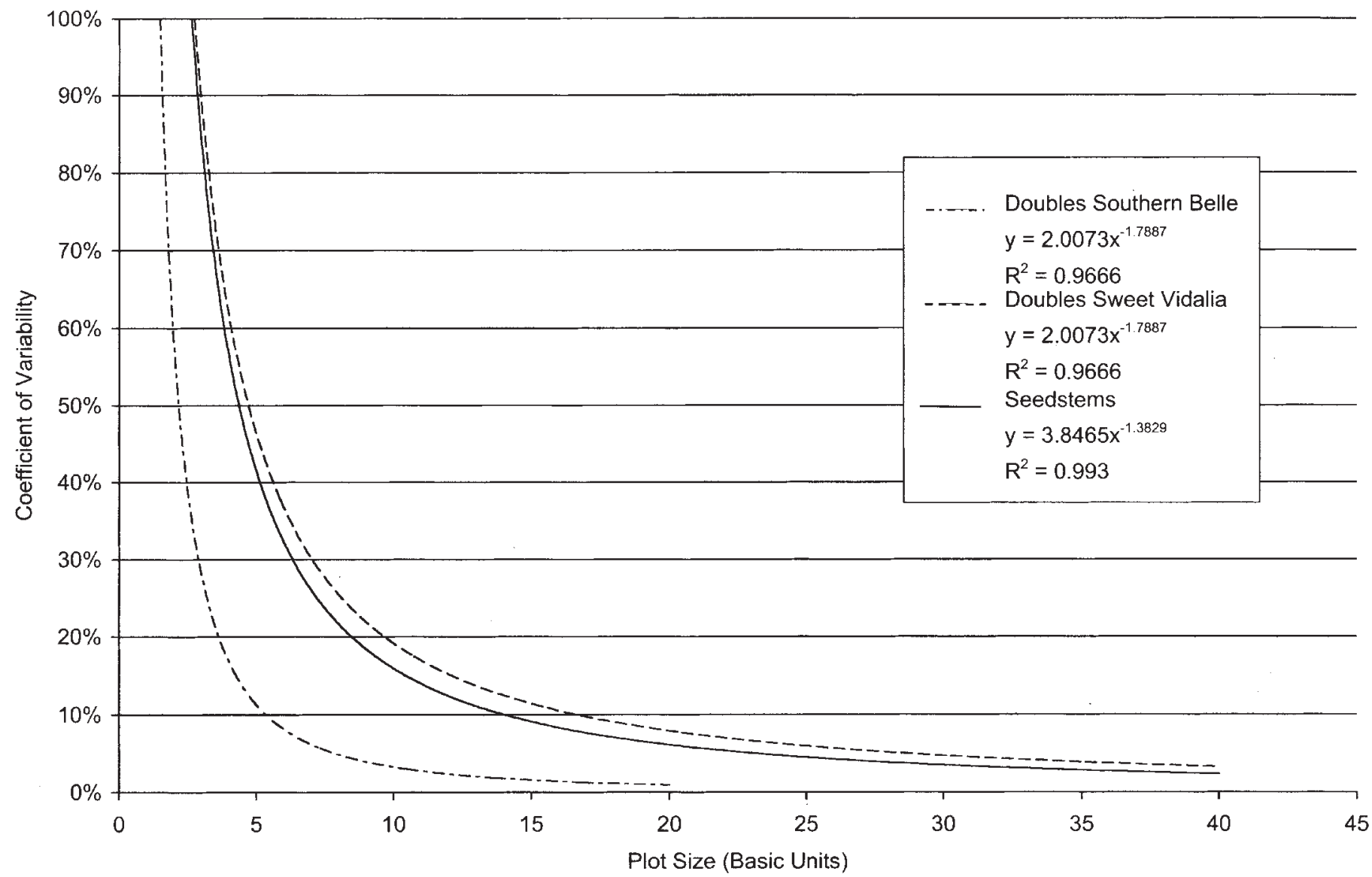

Fig. 6. Power trendline plots of coefficients of variability against plot size for seedstems and doubles.

the trendlines have a maximum curvature near plot sizes with two basic units with detections across all replications below $5 \%$ of the mean (Fig. 10). $R^{2}$ values for all trendlines were above 0.87 .

For 'Sweet Vidalia' doubles by Hatheway's method, a plot size of five basic units with seven replications will result in a true difference of $22 \%$ of the mean (Fig. 11). A plot size of eight basic units and four replications will result in a $23 \%$ mean difference. Plot sizes of eight basic units and five replications as well as 10 basic units and three replications, and 20 basic units and four replications all have mean differences below $20 \%$. A plot size of 40 basic units had mean differences below $10 \%$ regardless of the number of replications. With Cochran and Cox's method, all of the trendlines for 'Sweet Vidalia' doubles have a maximum curvature near plot sizes with two basic units with detections across all replications below $5 \%$ of the mean (Fig. 12), which is similar to the results with 'Southern Belle'. $R^{2}$ for all trendlines was above 0.95 .

Purple blotch/Stemphylium(PB/S) InCIDENCE. Although no attempt was made to distinguish between purple blotch and Stemphylium, a microscopic survey of disease lesions in the 2001-02 season indicated that $\approx 60 \%$ of infected leaves contained only Stemphylium conidia, $\approx 20 \%$ contained a mixture of Stemphylium and purple blotch, and 20\% contained just purple blotch.

Bartlett's chi-square test for homogeneity of variance for $\mathrm{PB} / \mathrm{S}$ 


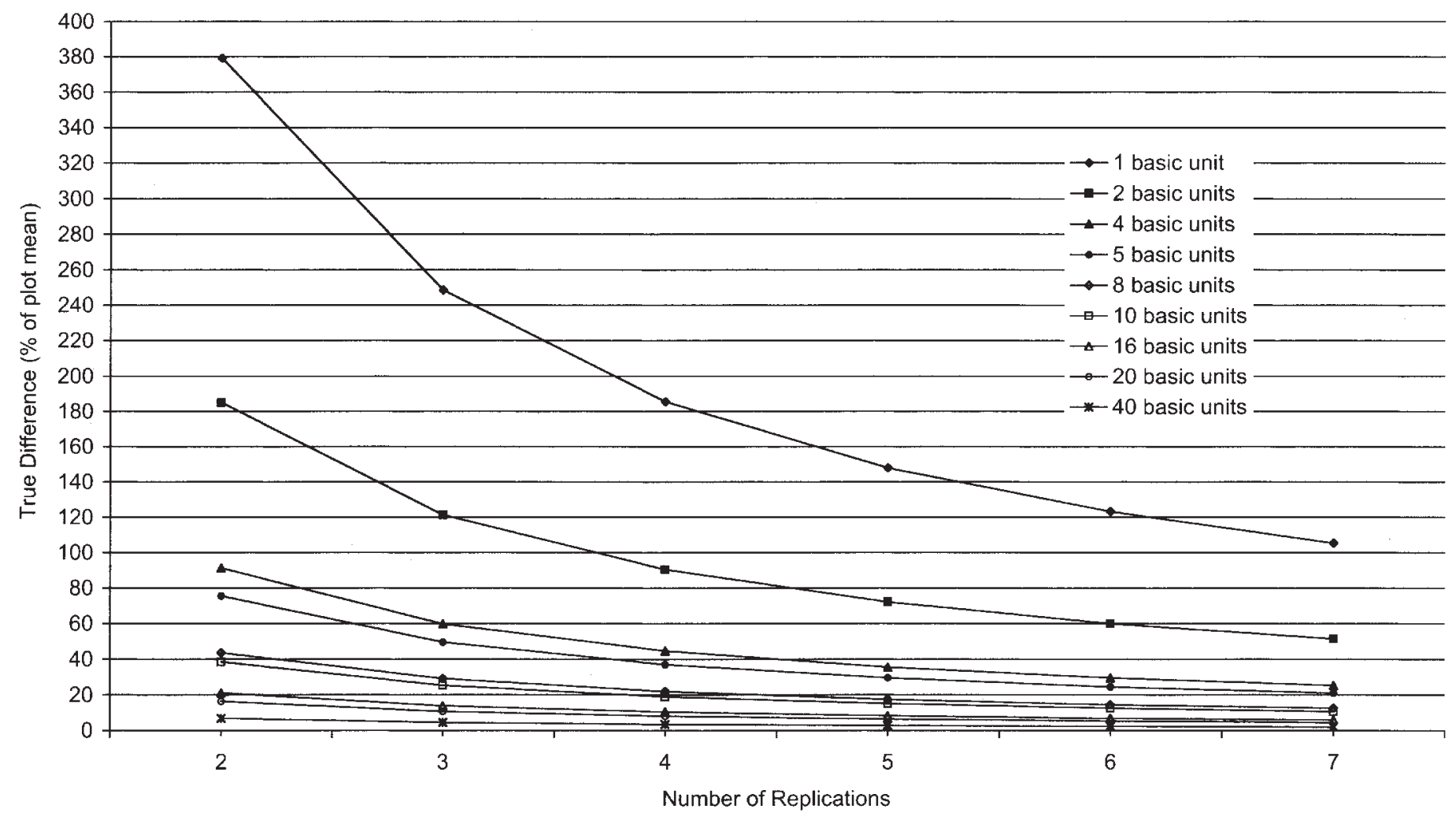

Fig. 7. Hatheway's Method for true differences as affected by the number of replications and plot size for seedstems.

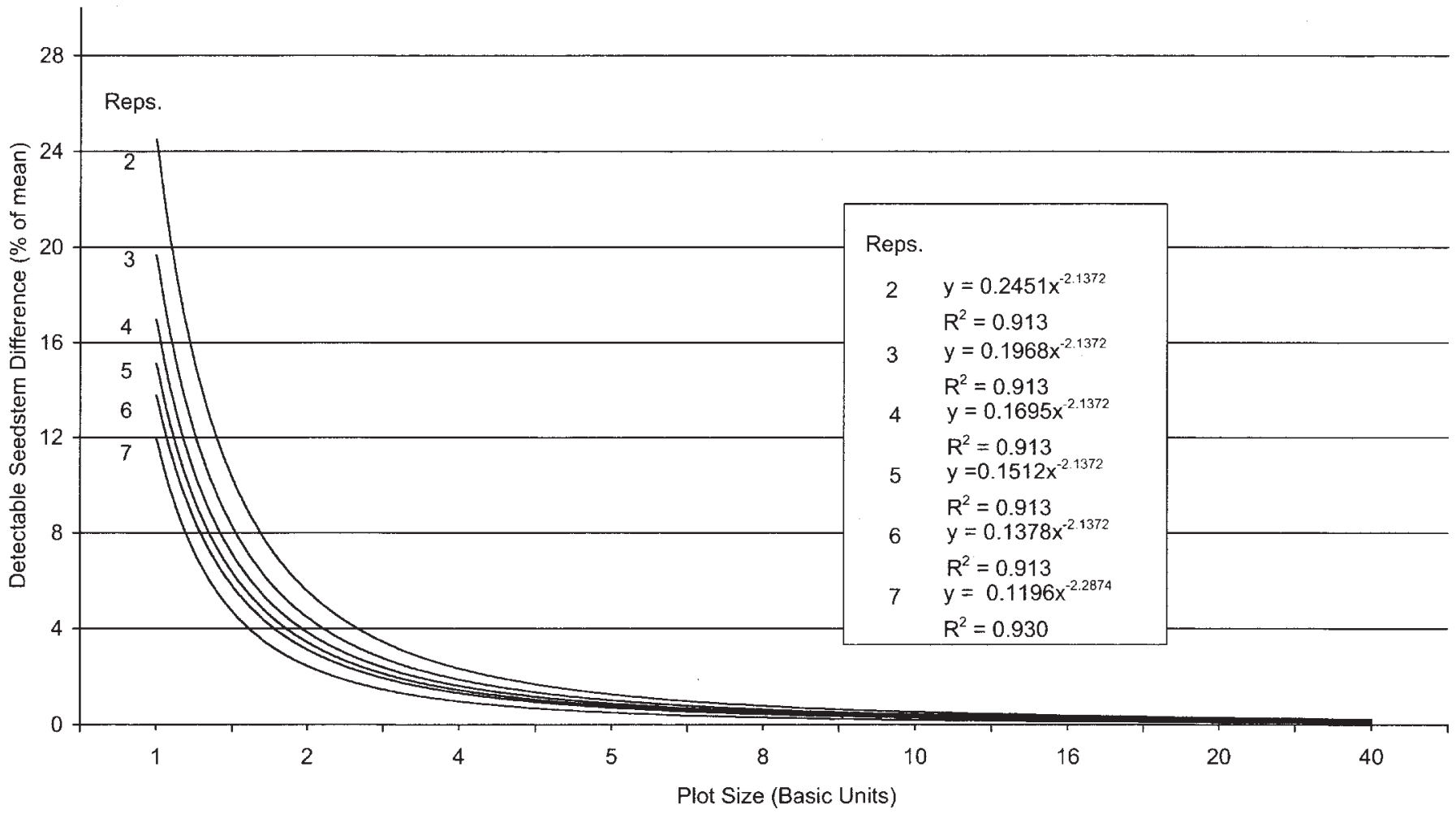

Fig. 8. Power trendlines for detectable seedstem differences as a function of plot size for different number of replications.

detected a difference in variance between plot sizes of one and two basic units (Table 7). In addition, variance differences for PB/S occurred between plot sizes of two and four, four and eight, five and eight, and eight and 10 basic units. For an LSD that is below
$5 \%$ of the mean number of lesions of 55 for $\mathrm{PB} / \mathrm{S}$ a plot size of two basic units and four replications is required (Table 8).

Plotting coefficient of variability against plot size for $\mathrm{PB} / \mathrm{S}$ indicated a maximum curvature of about five basic units (Fig. 
Table 5. Between plot variance $\left[\mathrm{V}_{(\mathrm{x})}\right]$, variance per unit area $\left(\mathrm{V}_{\mathrm{x}}\right)$, and coefficient of variability for bulb doubling for short-day onions grown in Georgia.

\begin{tabular}{|c|c|c|c|c|}
\hline $\begin{array}{l}\text { Basic } \\
\text { unit }\end{array}$ & $\begin{array}{c}\text { Between plot } \\
\text { variance } \\
\mathrm{V}_{(\mathrm{x})}\end{array}$ & $\begin{array}{c}\text { Variance per } \\
\text { unit area } \\
\mathrm{V}_{\mathrm{x}}\end{array}$ & df & $\begin{array}{c}\text { Coefficient } \\
\text { of variability } \\
(\%)\end{array}$ \\
\hline \multicolumn{5}{|c|}{ Southern Belle } \\
\hline 1 & 19.5 & $19.48 \mathrm{a}^{\mathrm{z}}$ & 39 & 161.6 \\
\hline 2 & 7.1 & $1.79 \mathrm{~b}$ & 19 & 48.9 \\
\hline 4 & 5.2 & $0.32 \mathrm{c}$ & 9 & 20.8 \\
\hline 5 & 3.9 & $0.16 \mathrm{c}$ & 7 & 14.4 \\
\hline 8 & 1.4 & $0.02 \mathrm{c}$ & 4 & 5.3 \\
\hline 10 & 1.8 & $0.02 \mathrm{c}$ & 3 & 4.9 \\
\hline 20 & 0.1 & $0.00 \mathrm{c}$ & 1 & 0.5 \\
\hline \multicolumn{5}{|c|}{ Sweet Vidalia } \\
\hline 1 & 14.8 & $14.8 \mathrm{a}$ & 79 & 366.8 \\
\hline 2 & 9.5 & $2.4 \mathrm{~b}$ & 39 & 146.6 \\
\hline 4 & 6.3 & $0.4 \mathrm{c}$ & 19 & 59.8 \\
\hline 5 & 7.2 & $0.3 \mathrm{c}$ & 15 & 51.2 \\
\hline 8 & 4.2 & $0.1 \mathrm{~d}$ & 9 & 24.3 \\
\hline 10 & 4.4 & $0.0 \mathrm{~d}$ & 7 & 19.9 \\
\hline 16 & 2.7 & $0.0 \mathrm{~d}$ & 4 & 9.8 \\
\hline 20 & 2.6 & $0.0 \mathrm{~d}$ & 3 & 7.7 \\
\hline 40 & 2.1 & $0.0 \mathrm{~d}$ & 1 & 3.4 \\
\hline
\end{tabular}

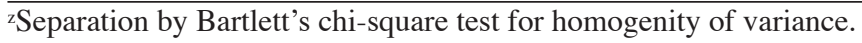

13). $\mathrm{PB} / \mathrm{S}$ had detectable differences below $20 \%$ by Hatheway's method for plot sizes of 10,16, 20, and 40 basic units regardless of the number of replications (Fig. 14). A detectable difference of $21 \%$ of the mean is possible with four replications and a plot size of four basic units for PB/S using Hatheway's method. In addition, detectable differences below $20 \%$ are possible with a plot size of five basic units and four replications and with a plot size of eight basic units and two replications. Maximum curvature of power trendline for Cochran and Cox's method occurred for plot size between two and four basic units regardless of number of replications for $\mathrm{S} / \mathrm{PB}$ (Fig. 15). $R^{2}$ for all trendlines was $>0.96$.

Botrytis leaf BLIGHT (BLB) INCIDENCE. For BLB there is a significant difference between variances for plot sizes with basic units one and two, two and four, four and five, five and eight, and eight and 40 basic units. Plotting coefficient of variability against plot size for BLB indicated a maximum curvature of about five basic units (Fig. 13).

For BLB the average percent leaf coverage is calculated at $4.2 \%$. Because a percentage is not additive as the plot size increases, this value remains approximately the same. An LSD below $5 \%$ of the mean percent BLB of $4.2 \%$ would require a plot size of four basic units and three replications. Several of the LSD values are not reported because they are negative due to an anomaly of the back transformations.

True differences between means is possible with a plot size of four basic units and four replications that is below $20 \%$ by Hatheway's method for BLB (Fig. 15). In addition, a plot size of eight basic units and two replications will result in a detectable difference below $20 \%$. A plot size of five basic units and three replications results in detectable differences of $21 \%$. Plot sizes with basic units of $10,16,20$, or 40 , regardless of number of replications, had detectable differences below $20 \%$. Finally, trendlines all had maximum curvature by Cochran and Cox's method for plot sizes around two basic units, regardless of the number of replications (Fig. 16). $R^{2}$ values were all above 0.83 .

Table 6. Computed LSD values for number of doubles based on number of replications and plot size $(P \leq 0.05$, treatment df $=30)$ for short-day onions grown in Georgia.

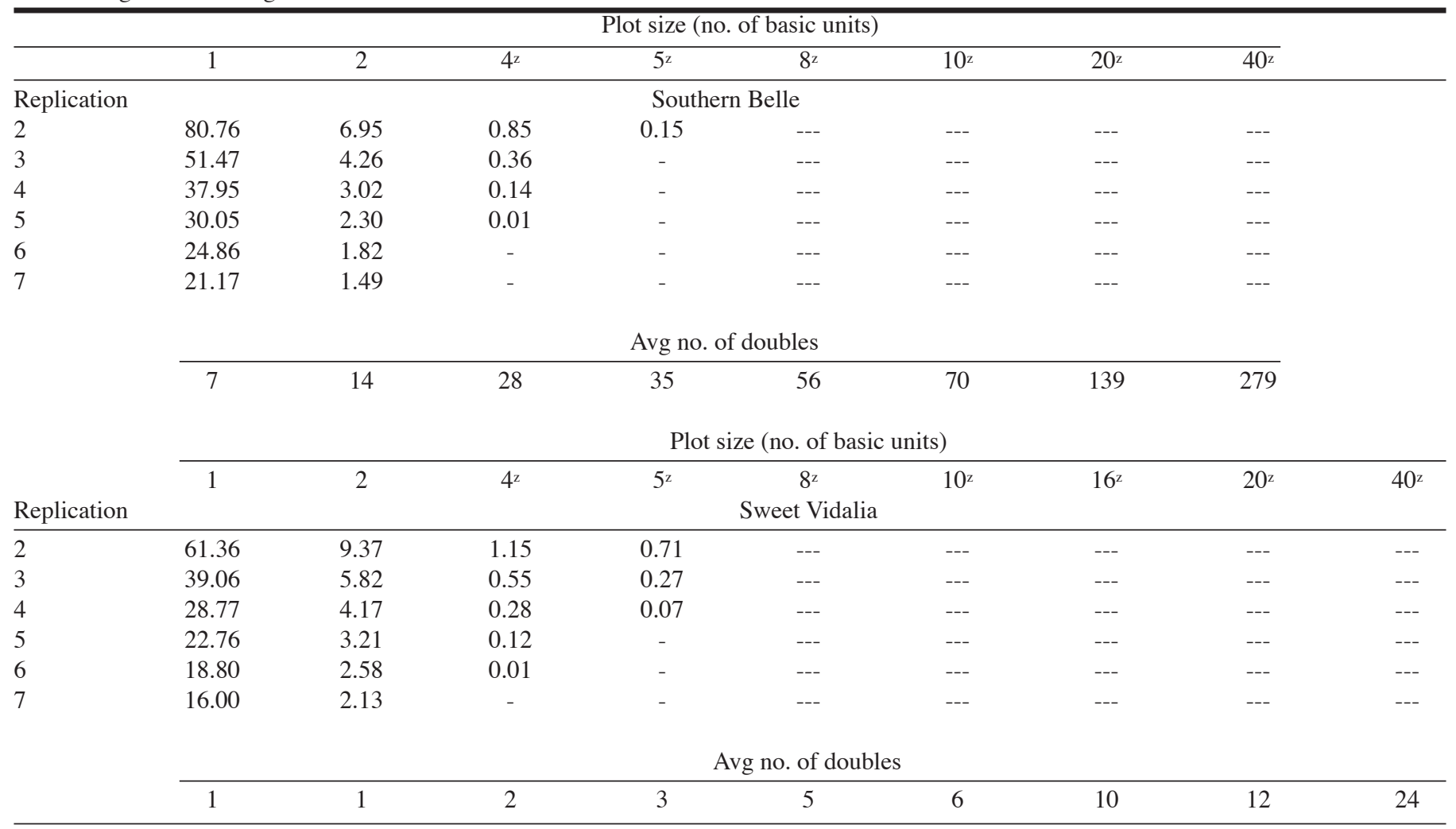

zBecause of an anomaly in back transforming these data, those values below 0 are not shown 
and variances based on plot size can be computed and compared. We used a level of $5 \%$ of the mean for a computed LSD as a good indicator of an appropriate plot size per replication combination; however, others may select a different level as circumstances and material dictate. We test 28 to 32 cultivars each year in our trials, hence the treatment degrees of freedom we selected was 30 with a $P \leq 0.05$. LSD values generally are not suitable for detecting differences between large numbers of treatments because of the increased chance of Type I errors, but in this case we are only demonstrating the potential for detecting differences.

In both years, using a detectable difference of $5 \%$ of the mean for an LSD resulted in a five basic unit plot $\left(13.5 \mathrm{~m}^{2}\right)$ with four replications as fitting the criteria. This suggests that it is a reasonable method for estimating these parameters in onions because results were similar over 2 years.

Plotting coefficient of variability against plot size and visualizing the maximum curvature is also a reasonably easy method for determining optimum plot size. The drawback of the method is that there is no estimate for the number of replications. For yield, the curves for the two seasons evaluated are relatively close indicating that the method is reasonable for estimating plot size.

Hatheway's method has the disadvantage of requiring a more complex calculation including calculating Smith's adjusted index of soil heterogeneity. For yield, the detectable yield differences were similar for both seasons.

Cochran and Cox's method, by contrast, takes a different approach to the problem and thus the selected thresholds are different. With Hatheway's method we used a threshold of $20 \%$ and with Cochran and Cox's we used a threshold of $10 \%$ for yield. These thresholds are purely arbitrary and other researchers could use different values based on the situation and experience with the crop. Cochran and Cox's method results in thresholds below $10 \%$ with a maximum curvature of the mean for plots between two and four basic units regardless of the number of replications.
Table 7. Between plot variance $\left[\mathrm{V}_{(\mathrm{x})}\right]$, variance per unit area $\left(\mathrm{V}_{\mathrm{x}}\right)$, and coefficient of variability for purple blotch/Stemphylium and Botrytis leaf blight, 2001-02 season for short-day onions variety Sweet Vidalia grown in Georgia.

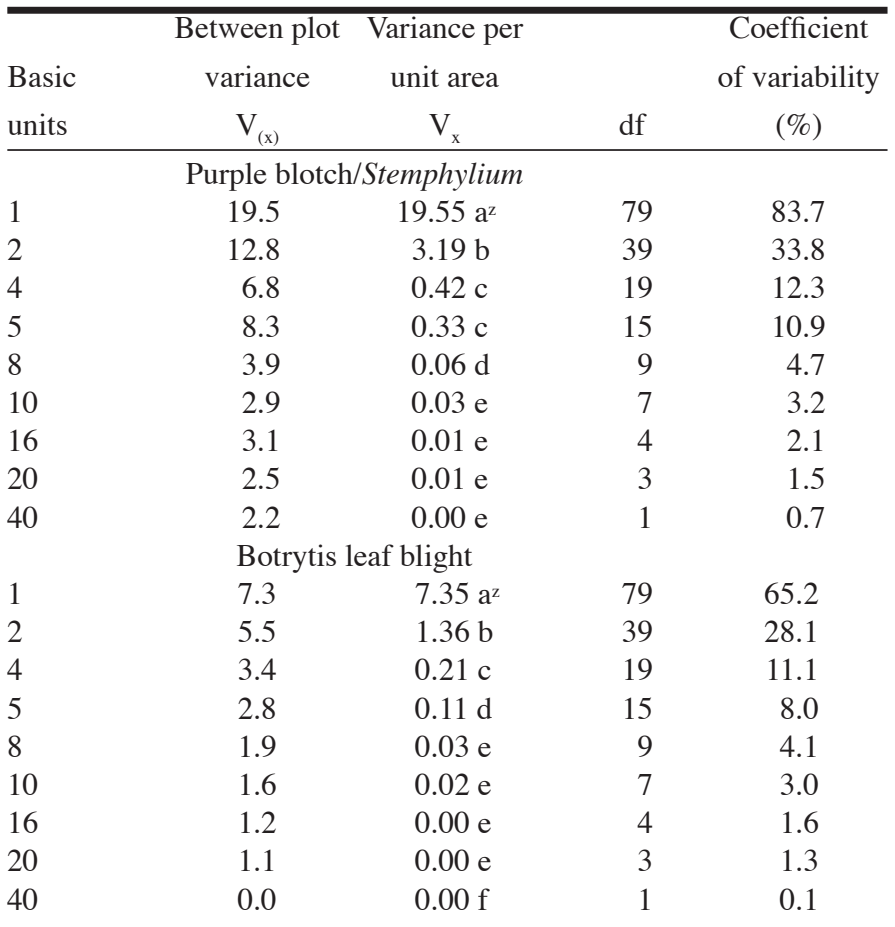

${ }^{{ }^{2} \text { Separation by Bartlett's chi-square test for homogenity of variance }(P}$ $\leq 0.05)$.

Based on our experience this plot size appears to be too small for determining yield, but it should be noted that researchers are generally trying to minimize the use of resources while maximiz-

Table 8. Computed LSD values based on number of replications and plot size for purple blotch/Stemphylium and botrytis leaf blight $(P \leq 0.05$, treatment $\mathrm{df}=30$ ) for short-day onions cultivar Sweet Vidalia grown in Georgia.

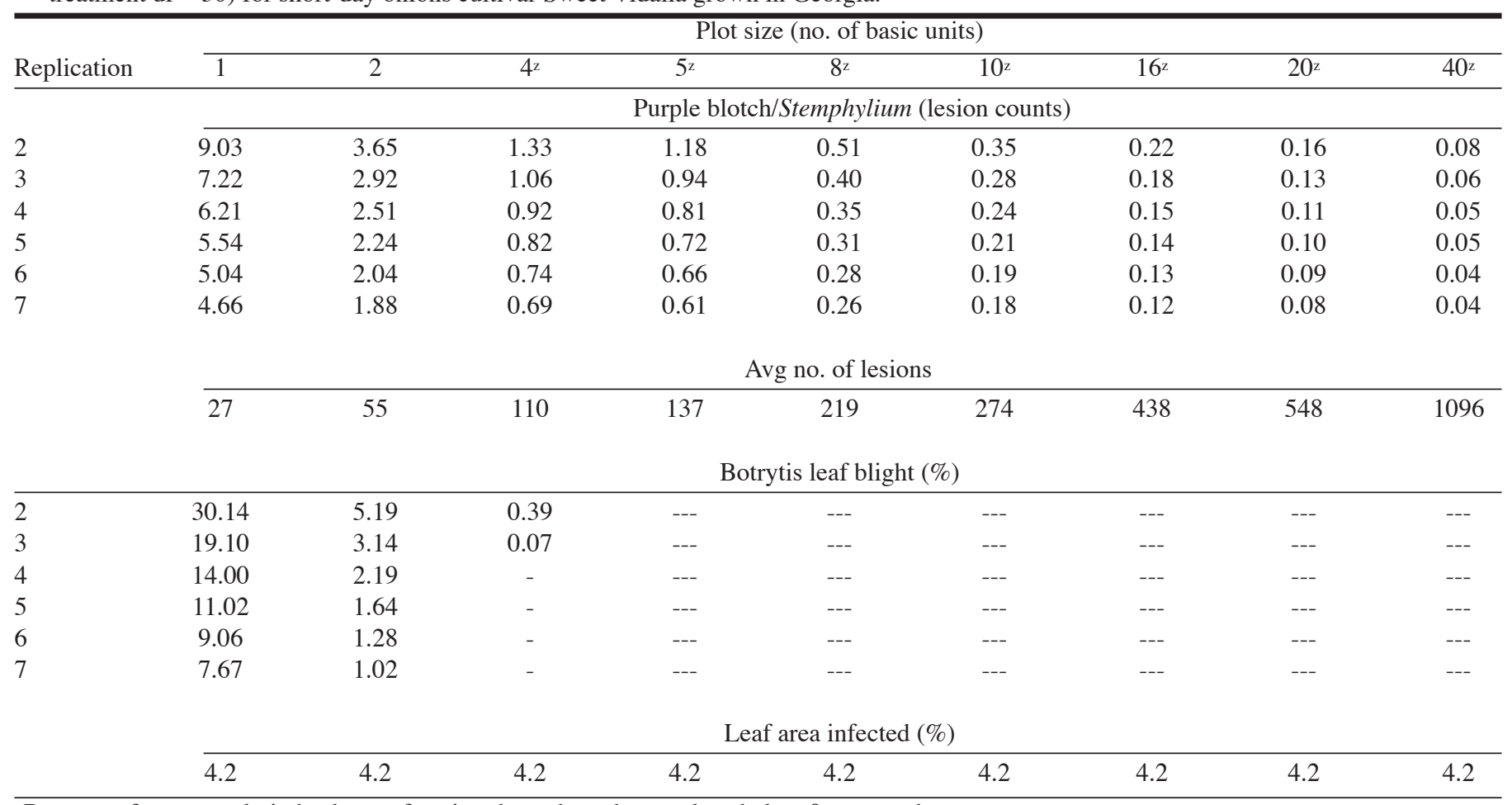

zBecause of an anomaly in back transforming these data, those values below 0 are not shown. 


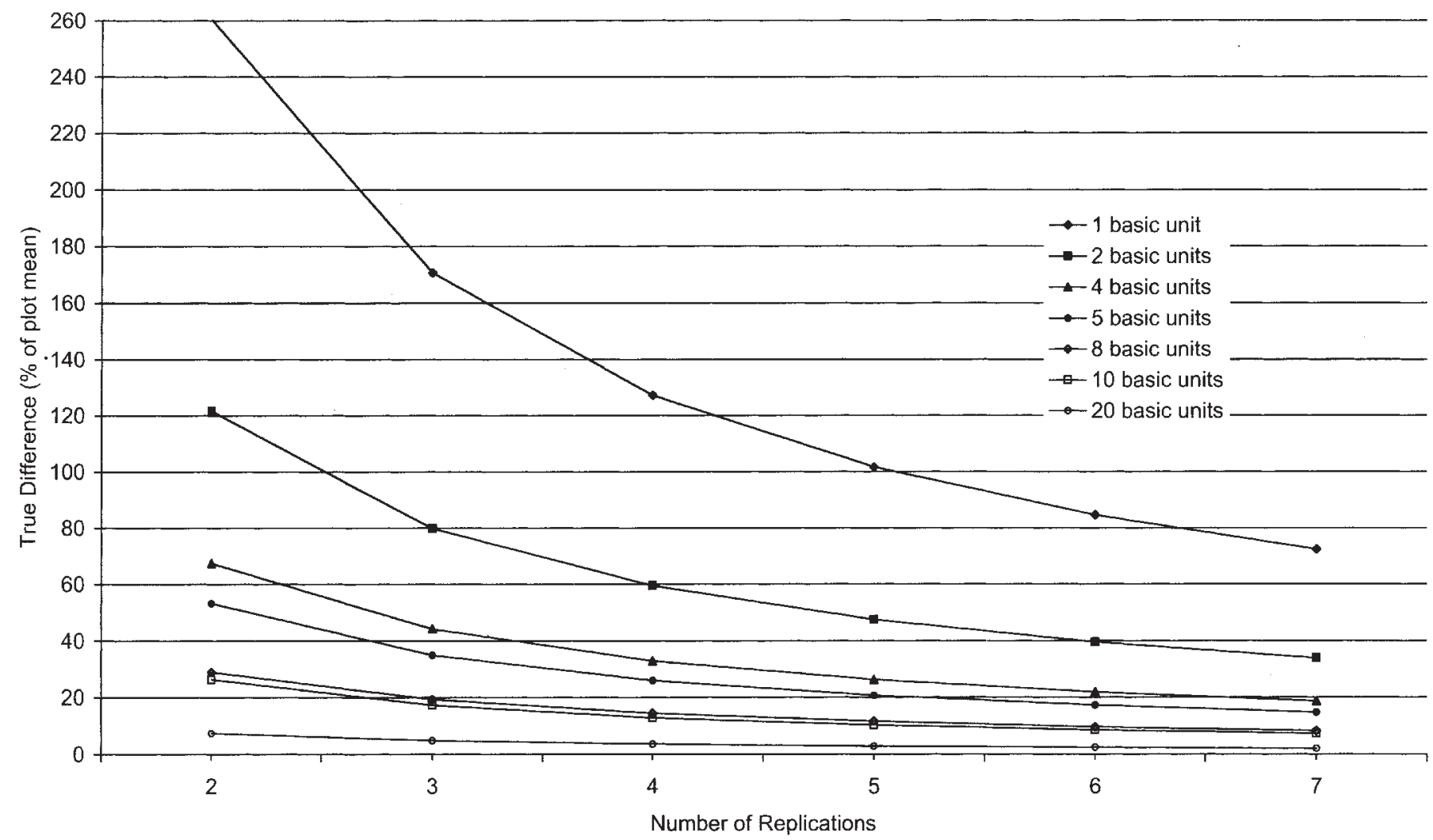

Fig. 9. Hatheway's Method for true differences affected by the number of replications and plot size for 'Southern Belle' bulb doubles.

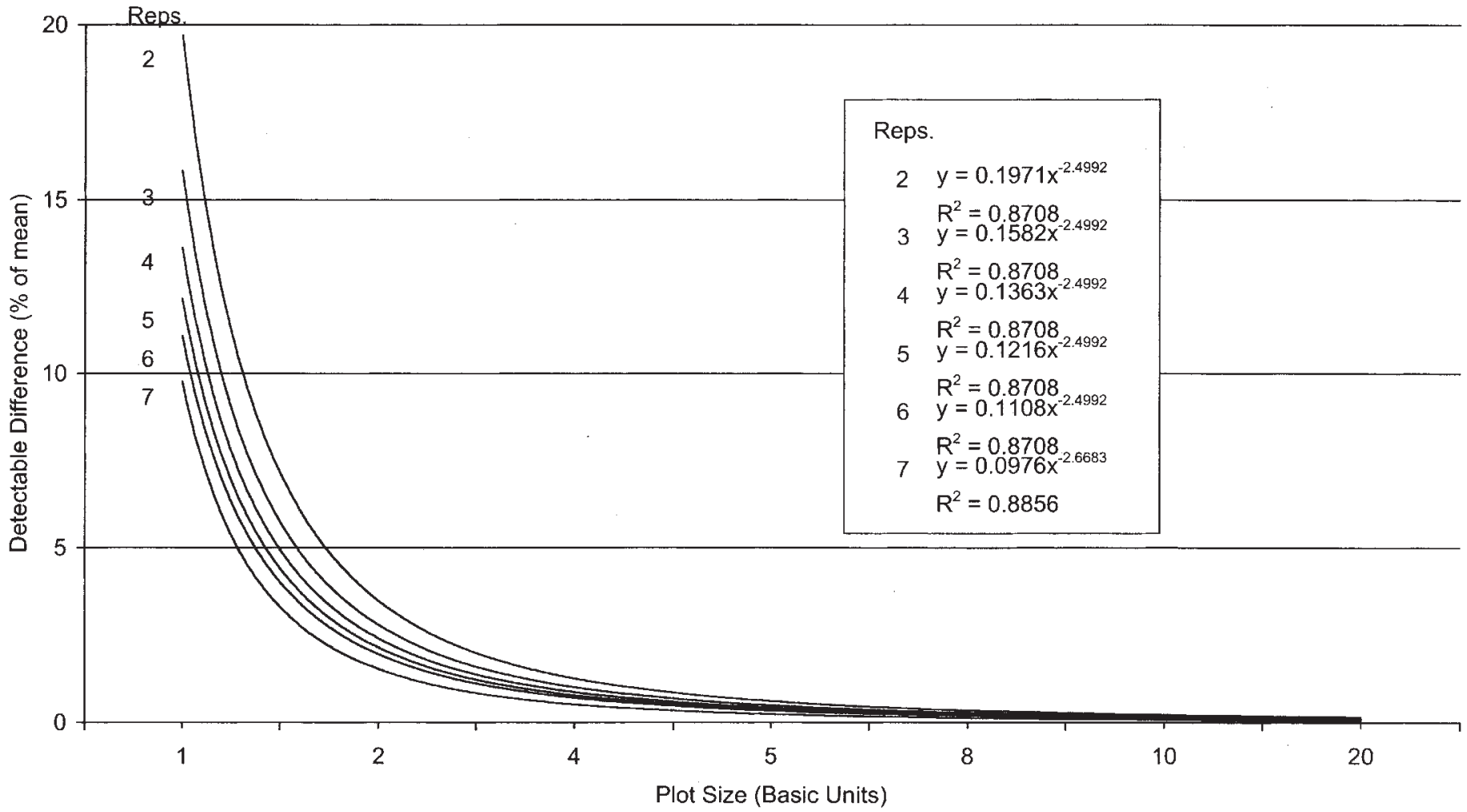

Fig. 10. Power trendlines for detectable differences of 'Southern Belle' doubles as a function of plot size for different number of replications. 


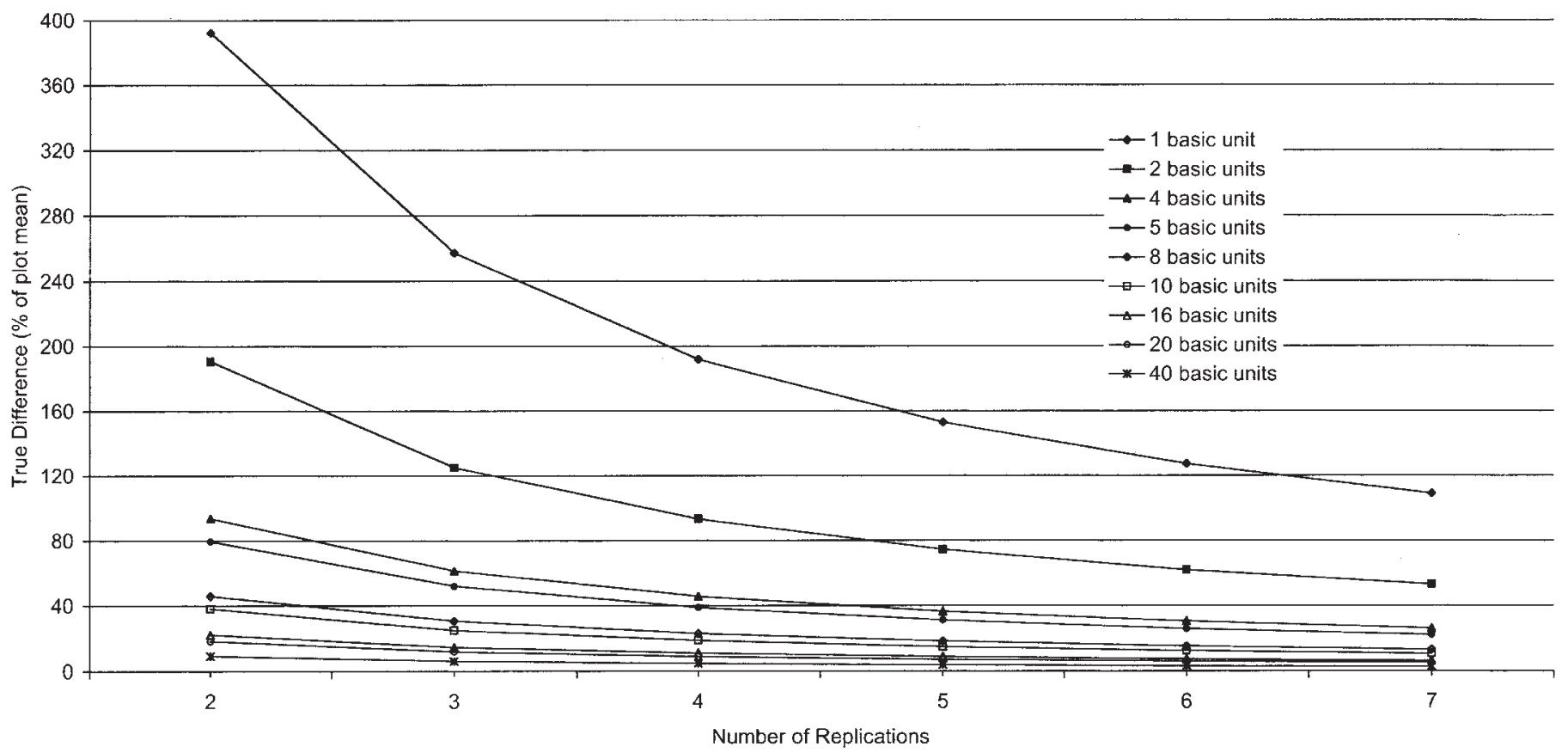

Fig. 11. Hatheway's Method for true differences as affected by the number of replications and plot size for 'Sweet Vidalia' bulb doubles.

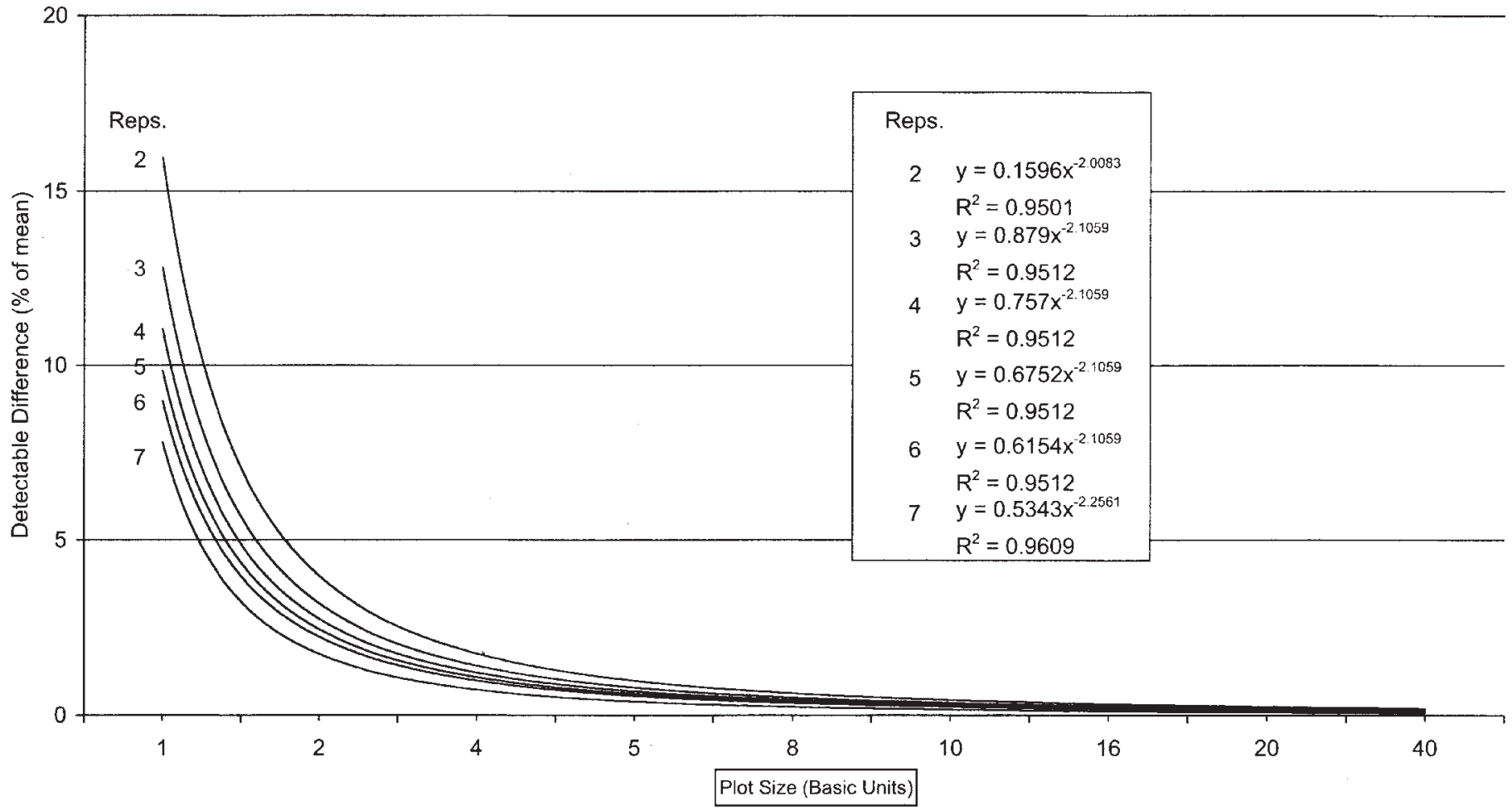

Fig. 12. Power trendlines for detectable differences of 'Sweet Vidalia' doubles as a function of plot sizes for different number of replications.

ing the ability to detect differences.

Ambiguity between the methods makes it difficult to select a specific plot size/replication combination; however, overall a plot size of four to five basic units and three to five replications appears to be appropriate for estimating yield although some estimates suggested plot sizes as high as seven or eight basic units or smaller plot sizes (two basic units) with more replications.

Using Bartlett's chi-square to detect differences in variances with respect to seedstems also requires some judgment. Although there are no overlaps in the differences between variances, differences are apparent between the smallest plot sizes, one and two basic units. Because we are dealing with counts (number of 


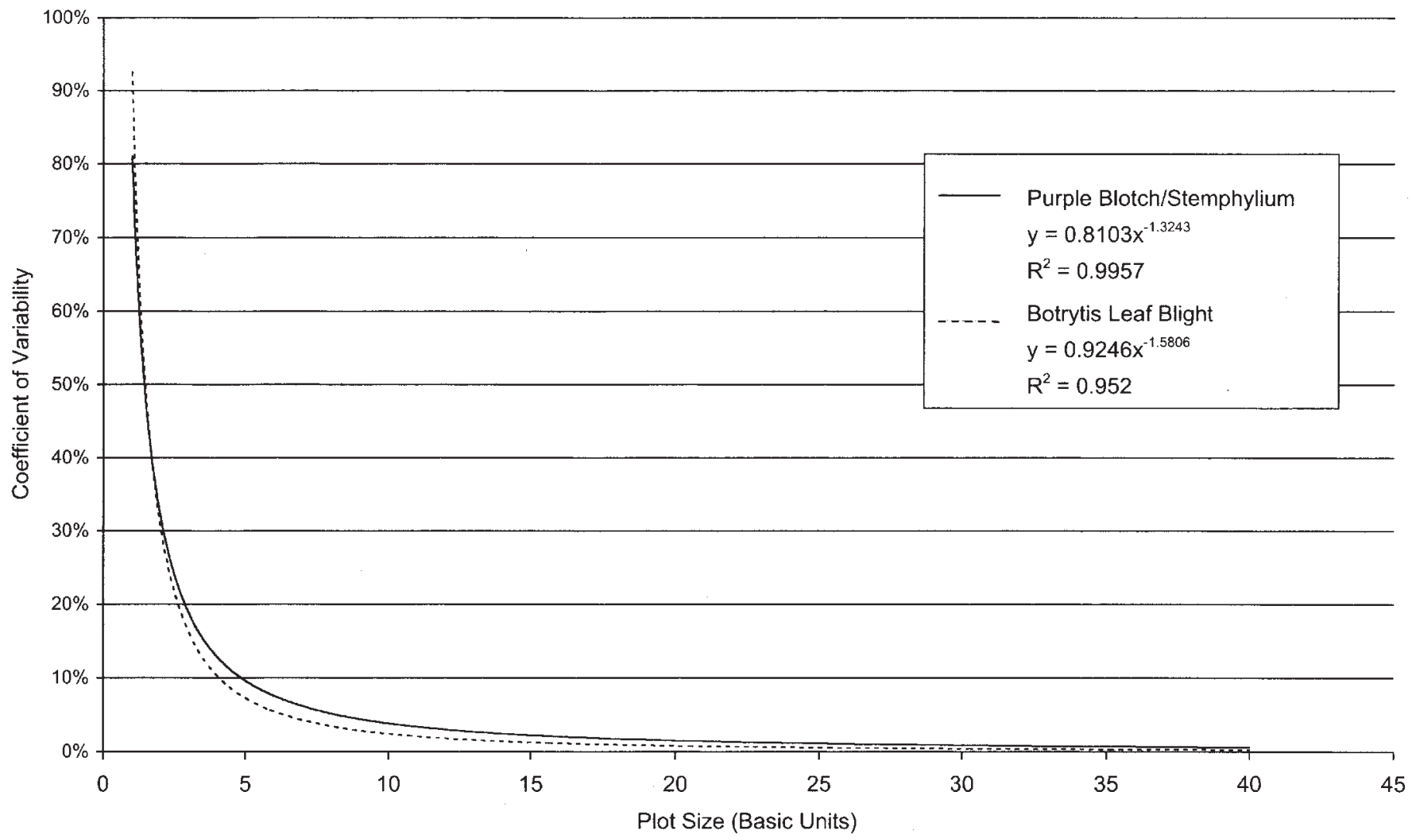

Fig. 13. Power trendline plots of coefficient of variability against plot size for purple blotch/Stemphylium and botrytis leaf blight.

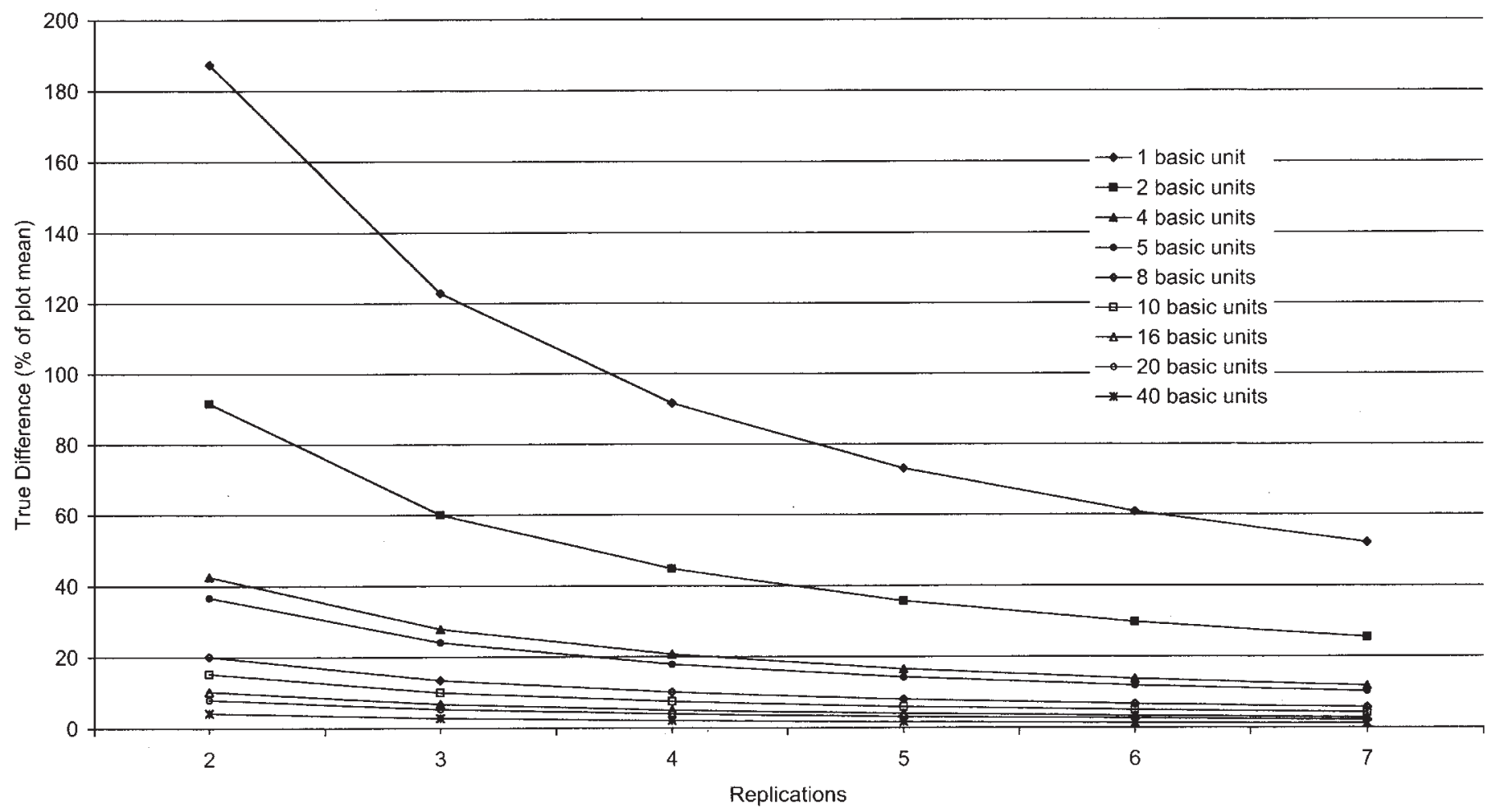

Fig. 14. Hatheway's Method for true differences as affected by the number of replications and plot size for purple blotch/Stemphylium. 


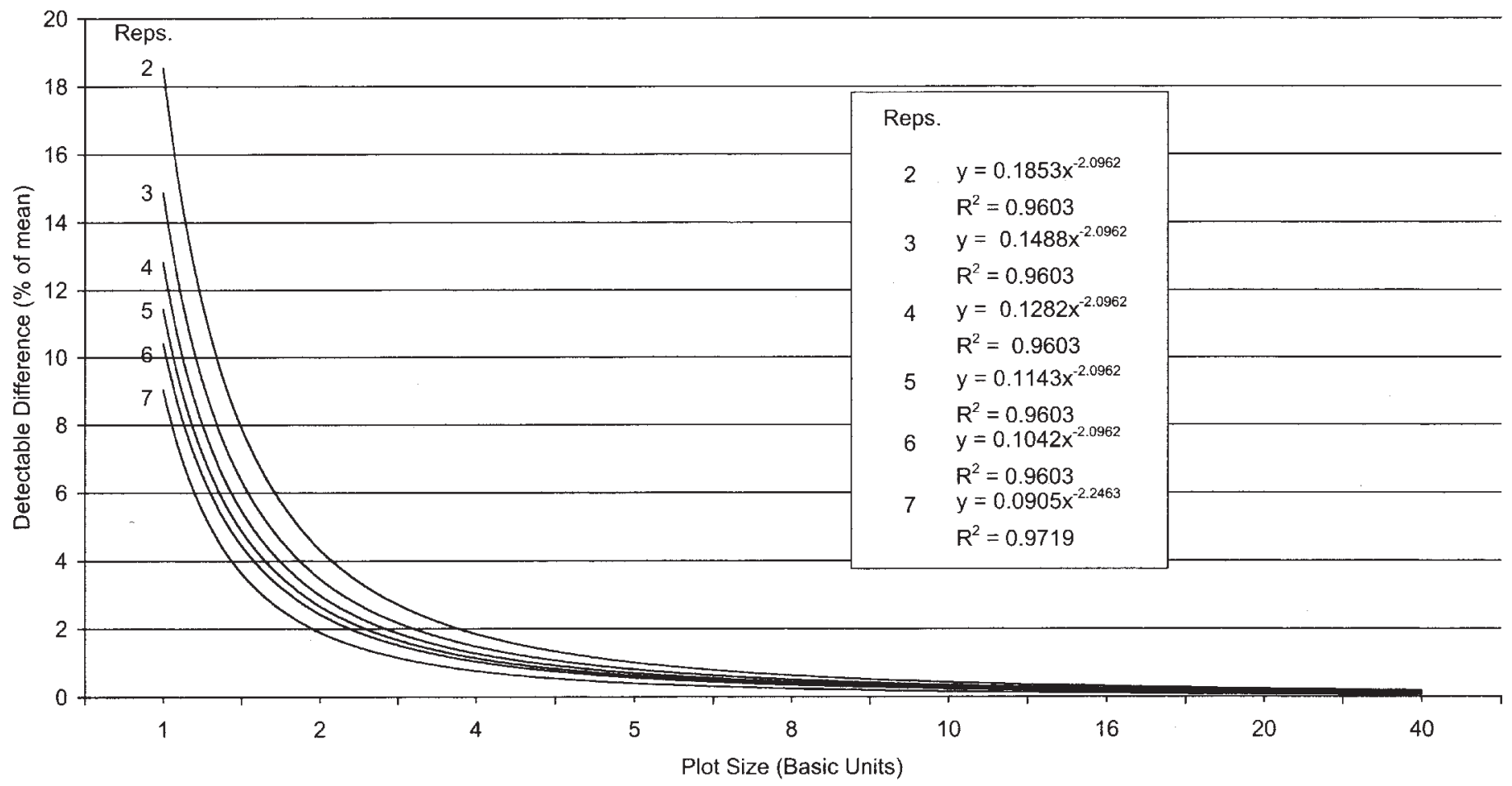

Fig. 15. Power trendlines for detectable differences of purple blotch/Stemphylium as a function of plot size for different number of replications.

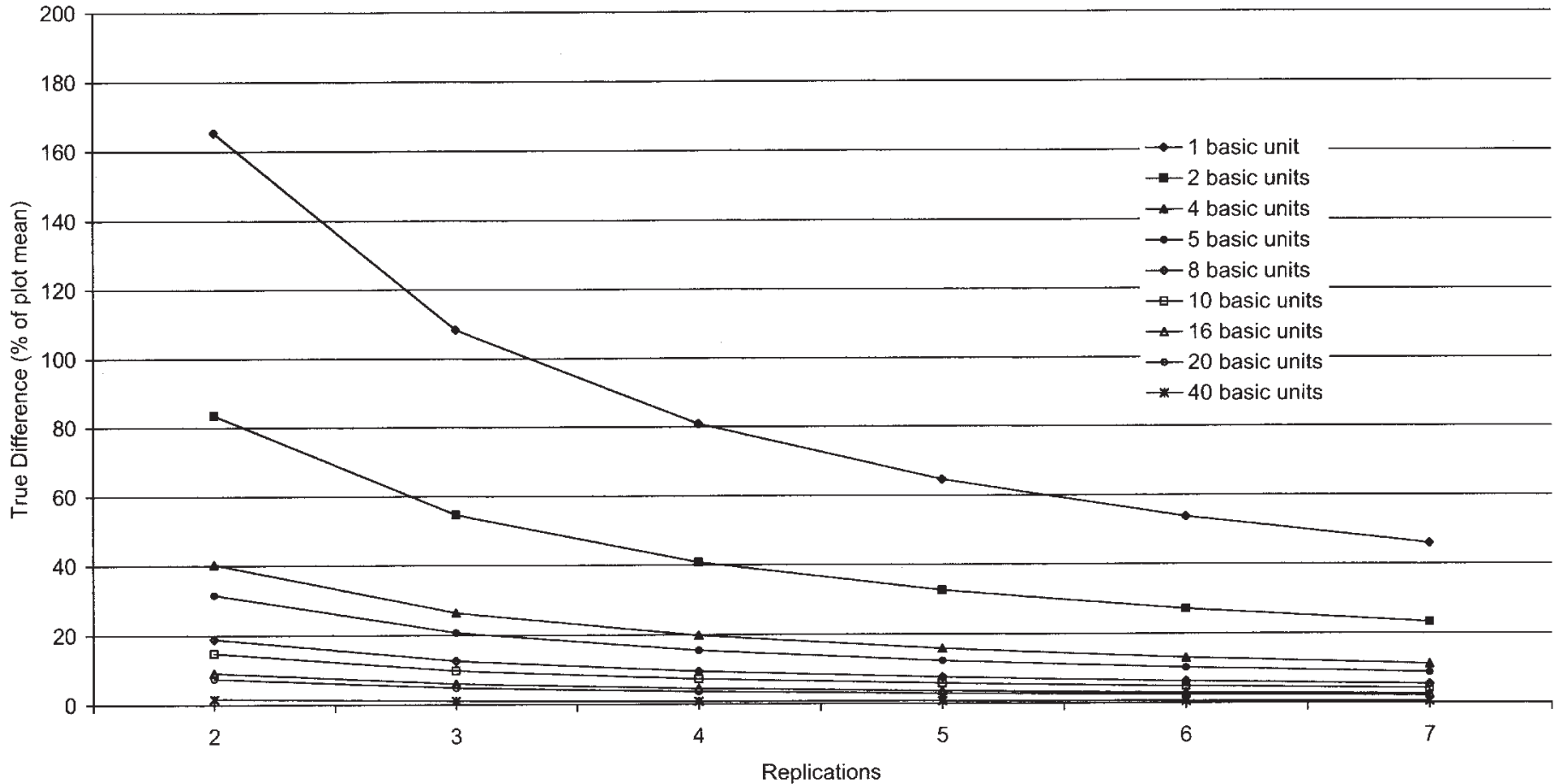

Fig. 16. Hatheway's Method for true differences as affected by the number of replications and plot size for botrytis leaf blight.

seedstems per plot), plots that are too small may misrepresent the true nature of the number of seedstems among treatments. Further, this characteristic is heavily influenced by environmental factors, thus there may be considerable differences in the number of seedstems from year to year. Temperature, time of planting, and cultivar are just a few of the influences on seedstem formation.
There were differences by Bartlett's chi-square for seedstems between five and eight basic unit plots, but there were no differences between the eight basic unit plot and the 10 or 16 basic unit plots. This suggests that five basic unit plots might be the most appropriate for detecting seedstems.

Because seedstems as well as bulb doubling and $\mathrm{PB} / \mathrm{S}$ are count 


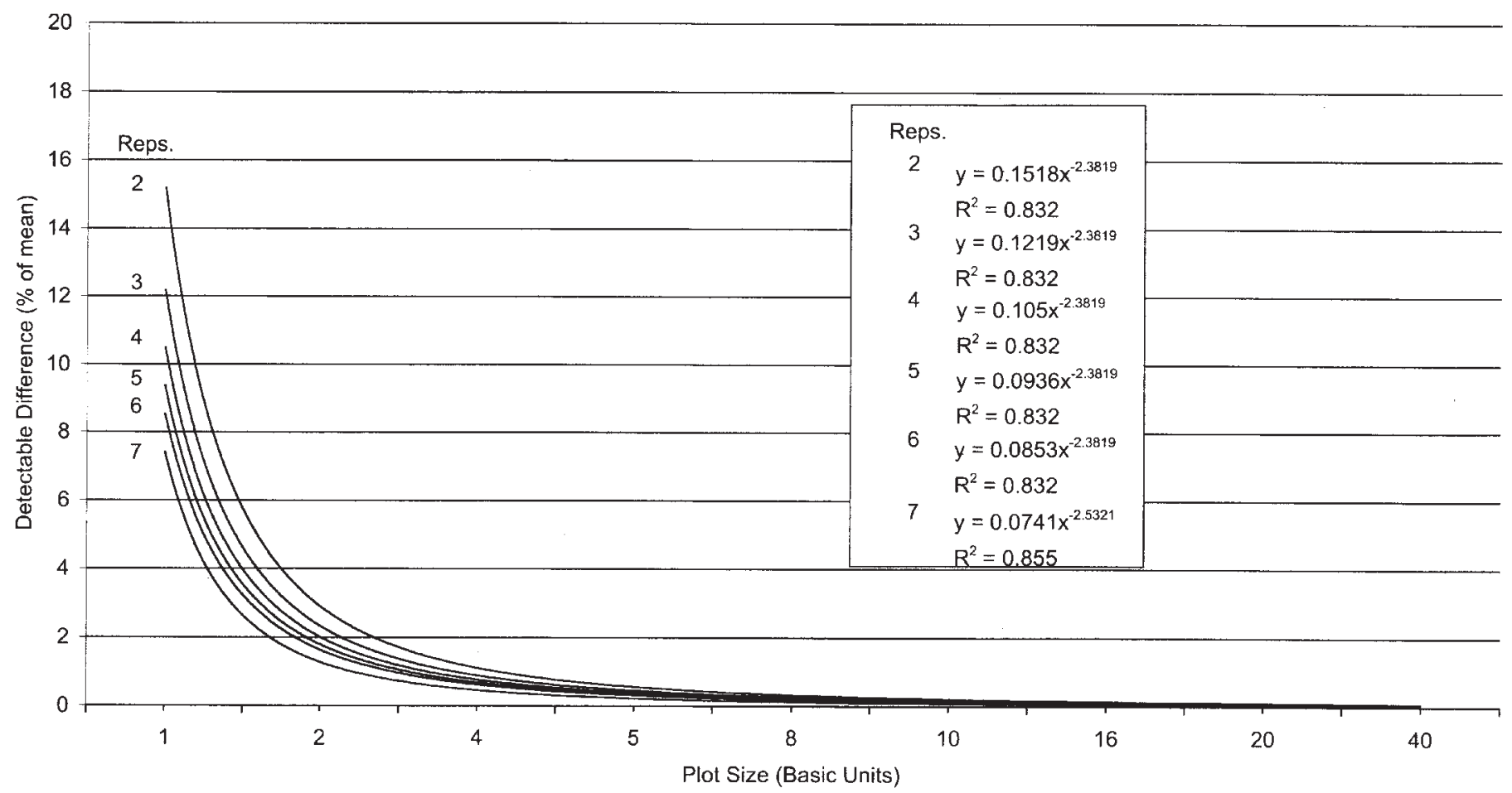

Fig. 17. Power trendlines for detectable differences of botrytis leaf blight as a function of plot sizes for different number of replication.

data, transformation is critical before making calculations. Results with untransformed data were dramatically different (data not shown). Back transforming the data resulted in negative values for some of the LSD values computed for seedstem, bulb doubling, and BLB (data not shown).

Power trendlines of the Cochran and Cox calculations for seedstems, doubles, and disease incidence were much lower than for yield. This suggests that this method of determining plot size and number of replications is influenced by the type of data, counts and percents in the former and yield in the latter.

Onion doubling is influenced by cultivar. 'Southern Belle' in the 2001-02 season had significantly more doubles than other cultivars, therefore it was included with 'Sweet Vidalia' to see how the number of doubles affects these analyses. Using Bartlett's chi-square, there were no detectable differences with plot sizes greater than four basic units with 'Southern Belle', which is also a break point for 'Sweet Vidalia' and suggests that this would be a good plot size for determining treatment differences due to doubling with either 'Southern Belle' or 'Sweet Vidalia'.

By contrast, plotting the coefficient of variability against plot size for 'Southern Belle' and 'Sweet Vidalia' resulted in a maximum curvature for 'Southern Belle' with a smaller plot size compared to 'Sweet Vidalia'. This indicates the effect the number of doubles has on determining optimum plot size. Intuitively, one would expect this to be the case where detecting differences would be possible on small plots that have relatively high counts. This is borne out in the LSD calculations as well as by Hatheway's method. It is not borne out with Cochran and Cox's method, however, which suggests that Cochran and Cox's method may not be the best suited method for determining plot size.

Bartlett's chi-square appears to work well with the disease data whether counted as in PB/S or a percent as with BLB. Differences between eight and 10 basic unit plot sizes for $\mathrm{PB} / \mathrm{S}$ and five and eight basic unit plot sizes for BLB suggest that optimum plot size for $\mathrm{PB} / \mathrm{S}$ is eight basic units and five basic units for BLB. This contrasts with the LSD calculations for $\mathrm{PB} / \mathrm{S}$ where an optimum plot size of two basic units with four replications meets the criteria of being below 5\% of the mean. Plotting the coefficient of variability against plot size or using Hatheway's method results in optimum plot sizes of five basic units with four replications for Hatheway's method. Cochran and Cox's method was lower, still suggesting a plot size of two basic units regardless of the number of replications.

The BLB data appear more consistent than the $\mathrm{PB} / \mathrm{S}$ data in determining optimum plot size and number of replications with an optimum plot size of four to five basic units and three to four replications.

Because data were collected incrementally from single beds in the 1999-2000, 2000-01,2001-02 season, no data were generated to determine the effect of plot shape on detecting differences. Not all methods gave the same results concerning the particular parameter under consideration, therefore researcher experience with the crop must also be employed in determining an optimum plot size and number of replications.

With calculations where both plot size and replication are estimated, they can be used to determine which combination would offer the best allocation of resources. For example, using Hatheway's method with PB/S a combination of five basic unit plot size and four replications gave approximately the same level of mean separation as eight basic unit plot size and two replications. Clearly the latter scenario uses less resources per cultivar.

In conclusion, there are different optimum plot size/replication combinations for different types of data as well as by the different methods used. Plot size and replication for yield is conservatively optimized at a plot size of five to eight basic units and four to five replications. For seedstems, the optimum is eight to 10 basic unit plot size with two to five replications. For high numbers of doubles as with 'Southern Belle' the optimum is plot size with four to five basic unit plot size and two to three replications. With relatively low numbers of doubles as with 'Sweet Vidalia' 
plot sizes of five to eight basic units and four to five replications would be optimum. For PB/S and BLB five to eight basic unit plot sizes and four to five replications would be ideal. Finally, the methods used appear to be better suited to some types of data and not others. Cochran and Cox's method worked well with yield data, but the estimates for counts and percents were low by our experience. Bartlett's chi-square worked better with the count and percent data, indicating a clear demarcation in variance compared to the yield data. Unfortunately, it does not estimate the number of replications. Both Hatheway's and the computed LSD methods appeared to give reasonable results regardless of data. The computed LSD values and plotting coefficient of variability against plot size methods have the advantage over Hatheway's or Cochran and Cox's methods in ease of calculation.

\section{Literature Cited}

Bhatt, H.M., P.R. Vasihnav, and V.B. Darji. 1998. Plot technique in potato (Solanum tuberosum L.). Gujarat Agr. Univ. Res. J. 24:67-72. Cochran, W.G. and G.M. Cox. 1957. Experimental designs. $2^{\text {nd }}$ ed. Wiley, New York.

Doherty, B.A. and W.O. Mizelle, Jr. 2001. Vegetable acreage and value estimates 2000. Univ. Ga. Ctr. Agribus. Econ. Dev. Annu. Rpt. SR01-08.

Esquivel, A. and R. Lopez. 1997. Effect of some variables on the sampling precision of Meloidgyne incognita (Nemata: Heteroderidae) on tobacco farms (in Spanish, English abstract). Agronomia Costarricense 21:163-170.

Gomez, K.A. and A.A. Gomez. 1984. Statistical procedures for agricultural research. $2^{\text {nd }}$ ed. Wiley, New York.

Gupta, J.P. and D. Raghavarao. 1971. Optimum size of plots for experiments on the weight of onion bulbs. Indian J. Hort. 28:234-236.

Hatheway, W.H. 1961. Convenient plot size. Agron. J. 53:279-280.

Lakhera, M.L., V.P. Singh, R.M. Sundar, and N.M. Patel. 1995. Optimum size and shape of plot for field experiments on gram. Agr. Univ. Res. J. 21:142-148.

Little, T.M. and F.J. Hills. 1978. Agricultural Experimentation Design and Analysis. Wiley, New York.

Oliveira, P.H. de and V. Estefanel. 1995. Optimal shape and size of plots for evaluation of experimental yields of potato. Ciencia Rural 25:205-208.

Peiretti, D.A., E.B. Biderbost, J.J. Carreras, and M.C. Nazar. 1990. Size and shape of garlic (Allium sativum L.) experimental plots (in Spanish, English abstract). Revista de Ciencias Agropecuarias - Universidad Nacional de Cordoba Facultad de Ciencias Agropecuarias 7:45-48.

Ramachander, P.R. and C.S. Pathak. 1989. Experimental techniques for onion experiments. Veg. Sci. 16:9-13.

Rampton, H.H. and R.G. Petersen. 1962. Relative efficiency of plot size and numbers of replications as indicated by yields or orchard grass seed in a uniformity test. Agron. J. 54:247-249.

Saad,A.M.M. 1996. The relative efficiency of some experimental designs from optimum plot size and plots for evaluating faba bean yield. Ann. Agr. Sci. Moshtohor. 34:799-810.

Saito, H. and M.Ohtake. 1996. Relations between plot size and reliability of experiments. Proc. Jpn. Soc. Sugar Beet Technol. 38:136-142.

Shamasundaran, K.S. and R.N. Bhat. 1997. Investigation on optimum size and shape of plots for rose. S. Indian Hort. 45:38-40.

Sharma, H.C. and S.S. Misra. 2000. Optimum plot size for estimating the incidence of white grubs Holotrichia (Lachnosteran) coriacea damaging potato crop in higher hills of Himachal Pradesh, India. Indian J. Entomol. 62:101-108.

Singh, R.P. 1989. Size and shape of plots and blocks for field trials on cabbage (Brassica oleracea var. capitata). Indian J. Hort. 46:255-260.

Singh, V.P., M.L. Lakhera, U.J. Upadhyaya, and N.M.Patel. 1998. Optimum plot size in multivariate approach and relative precision of experimental designs in chickpea. J. Maharashtra Agr. Univ. 23: $111-114$.

Szunics, L. and L. Balla. 1975. Plot size, number of replications and reliability of field trials of wheat in the random block design (in Hungarian, English abstract). Novenytermeles 24:119-126.

Thomas, H.L. and H.A Abou-El Fittouh. 1968. Optimum plot size and number of replications for estimating forage yield and moisture percentage. Agron. J. 60:549-550.

Urbano, E., G. Forbes, and M.E. Ordonez. 1994. Effect of the plot size on assessment of resistance to Phytophthora infestans in potato (Solanum tuberosum) (in Spanish, English abstract). Fitopatologia 29:137-140.

Vallejo, R.L. and H.A. Mendoza. 1992. Plot technique studies on sweetpotato yield trials. J. Amer. Soc. Hort. Sci. 117:508-511 